\title{
Hydrogen production from pine and poplar bio-oils by catalytic steam reforming. Influence of the bio-oil composition on the process
}

\author{
Remón J. ${ }^{\mathrm{a}}$, Broust F. ${ }^{\mathrm{b}}$, Volle G. ${ }^{\mathrm{b}}$, García L. ${ }^{\mathrm{a}^{*}}$, Arauzo J. ${ }^{\mathrm{a}}$ \\ ${ }^{\text {a }}$ Thermochemical Processes Group (GPT), Aragón Institute for Engineering Research \\ (I3A), Universidad de Zaragoza. Mariano Esquillor s/n, E-50018 Zaragoza, Spain. \\ *Corresponding author. Tel: +34 976 762194; Fax: +34 976 761879; e-mail: \\ luciag@unizar.es \\ ${ }^{\mathrm{b}}$ CIRAD-Persyt TA B-10/16, 73 avenue J.-F. Breton, 34398 Montpellier cedex 5, \\ France
}

\section{Abstract}

The catalytic steam reforming of four different aqueous fractions of bio-oil has been carried out in a fixed bed reactor at $650^{\circ} \mathrm{C}$ and atmospheric pressure using a Ni-Co/AlMg catalyst, employing a spatial time of $4 \mathrm{~g}$ catalyst $\mathrm{min} / \mathrm{g}$ organics. The chemical analysis of the aqueous fractions revealed that the source of biomass (pine or poplar sawdust) and the pyrolysis unit significantly influenced the chemical composition of these liquids. Depending on their chemical composition, the initial $\mathrm{H}_{2}$ yield varied from 0.101 to $0.182 \mathrm{~g} \mathrm{H}_{2} / \mathrm{g}$ organics and the initial $\mathrm{CO}_{2}$ yield from 0.814 to $1.28 \mathrm{~g} \mathrm{CO}_{2} / \mathrm{g}$ organics during their catalytic reforming. Regarding catalytic stability, higher catalyst deactivation took place during the reforming of the two pine bio-oil aqueous fractions. The reforming results of the four aqueous fractions have been correlated to their chemical compositions using statistical empirical additive models developed using the Bayesian Information Criterion (BIC). This strategy enabled the identification of the chemical compounds responsible for the most significant variations observed during the reforming of the liquids. The different proportions of acetic acid and furfural in the liquids had the greatest impact on the reforming results. Acetic acid was identified as a compound with low reactivity and low coke formation. In contrast, furfural was found 
to have high reactivity and a high tendency to produce coke in the reforming process.

Additional reforming experiments conducted with acetic acid, phenol, furfural, levoglucosan and guaiacol helped to confirm and explain the results obtained during the catalytic steam reforming of the aqueous fractions.

\section{Keywords:}

catalytic steam reforming; hydrogen; bio-oil composition; reactivity; catalyst deactivation

\section{Introduction}

An alternative method of producing a $\mathrm{H}_{2}$ rich gas is the catalytic steam reforming of the aqueous fraction of bio-oils. This $\mathrm{H}_{2}$ rich gas offers the opportunity to furnish a broad range of environmentally clean fuels and high value chemicals [1]. Depending on the reaction conditions and the catalyst used, different chemicals such as methanol, other alcohols and aldehydes may be produced from this $\mathrm{H}_{2}$ rich gas in a third generation biorefinery [2].

The catalytic steam reforming of the aqueous fraction of bio-oil first requires the separation of the bio-oil in two phases: the water-soluble fraction, containing the low molecular weight organics, and the insoluble fraction, enriched with lignin-derived compounds. This separation can be achieved by water addition [3], or by molecular distillation, as described in the work of Wang et al. [4]. The aqueous phase, being a 
complex mixture of different compounds such as acids, ketones, aldehydes, alcohols, sugars, phenols and more complex carbohydrates in water, can be catalytically reformed to produce a gas with a high $\mathrm{H}_{2}$ content. The non-soluble fraction of the bio-oil can be used for the production of high value added chemicals.

The composition of these aqueous fractions depends on the previous fast pyrolysis step, i.e. the biomass source, the reactor and the operating conditions under which the pyrolysis takes place [5]. Thus, the previous pyrolysis step will not only influence the composition of the bio-oils and the aqueous fractions produced from them, but also their performance when catalytically reformed.

The vast majority of studies dealing with the catalytic steam reforming of bio-oil and/or its aqueous fraction focus on studying the influence of the reactor type, catalyst, temperature and steam to carbon ratio on the process. Few studies evaluate how the chemical composition of the liquids affects the process. Due to the complex chemical composition of these liquids, three different approaches have usually been taken. One consists of studying the steam reforming of the most representative model compounds that constitute the aqueous fractions alone, while the other two are based on studying the catalytic steam reforming of simulated (mixtures of model compounds) or real biooil aqueous fractions.

The first approach deals with model compounds and permits an in-depth study of the different compounds alone, which is very useful for understanding reactivity and coke 
formation. In this context there are many works dealing with the reforming of different model compounds. However, not many of them provide a reliable comparison between hydrogen production and/or coke formation from different oxygenates under similar operating conditions. Bimbela et al. $[6,7]$ studied the reactivity of acetic acid, acetol and n-butanol using similar operating conditions over Ni-based catalysts in a fixed bed reactor. Medrano et al. [8] compared the catalytic steam reforming of acetic acid and acetol over Ni-based catalysts in a fluidised bed reactor. These works reported that acetol and butanol showed higher conversion and hydrogen production than acetic acid. The lower conversion obtained with acetic acid was the result of the progressive deactivation of the catalyst due to coke formation, as was illustrated by SEM images and TPO analyses of the used catalysts.

Rioche at al. [9] compared the catalytic steam reforming of acetic acid, acetone, ethanol and phenol using different catalysts: $\mathrm{Pt}$, $\mathrm{Rh}$ and $\mathrm{Pd}$ supported on $\mathrm{Al}_{2} \mathrm{O}_{3}$ or $\mathrm{CeZrO}_{2}$. The reactivity of the model compounds was studied using all the catalysts. Hydrogen production was as follows: phenol>acetone $>$ acetic acid $>$ ethanol. $\mathrm{Hu}$ and $\mathrm{Lu} \mathrm{[10]}$ studied the reactivity and the coke formation rate of acetic acid, ethylene glycol, acetone, ethyl acetate, m-xylene and glucose. They found that decomposition or polymerisation to carbonaceous deposits was the main route for coke formation in sugars and aromatic species such as glucose and m-xylene, while the large amount of by-products such as ethylene, carbon monoxide or acetone were the main sources of coke in the steam reforming of ethyl acetate, ethylene glycol and acetic acid. The reactivity of these species followed this order: acetic acid $>$ ethylene glycol $>$ acetone $>$ glucose $>$ ethyl acetate $>$ m-xylene, while coke formation was as follows: glucose $>\mathrm{m}$ xylene $>$ acetone $>$ ethyl acetate $>$ ethylene glycol $>$ acetic acid. 
Marquevich et al. [11] studied the catalytic steam reforming of acetic acid, m-cresol, benzyl ether, xylose, glucose and sucrose. Acetic acid, m-cresol and benzyl ether easily achieved their stoichiometric $\mathrm{H}_{2}$ potential, while sugars were more difficult to reform as they readily decomposed through pyrolysis in the reactor freeboard, producing char and gases before contacting the catalyst. Vagia et al. [12] studied the thermodynamics of the catalytic steam reforming of acetic acid, ethylene glycol and acetone. The effect of the temperature, the pressure and the $\mathrm{S} / \mathrm{C}$ ratio was studied in order to select the optimum reforming conditions. The comparison between the model compounds showed the following $\mathrm{H}_{2}$ theoretical production: acetone > ethylene glycol > acetic acid.

Wang et al. $[4,13,14]$ studied the reaction mechanism for the catalytic steam reforming of acetic acid, 2-propanone-1 hydroxy, furfural and phenol theoretically, using symmetric density functional theory calculations and experimentally employing $\mathrm{Ni}$ supported on waste coal ash catalysts. These calculations revealed the following reactivity of these compounds in the reforming process: furfural $>2$-propanone-1 hydroxy $>$ acetic acid $>$ phenol. The experimental study conducted with 2-propanone-1 hydroxy, acetic acid and phenol revealed the same trends in reactivity and hydrogen production predicted in the theoretical calculation study.

An intermediate approach consists of studying the catalytic steam reforming of simulated mixtures which represent the behaviour of the different chemical species in bio-oils in a more realistic manner than single model compounds. This strategy is very useful for studying interactions between some constituents of the bio-oils. Wu et al. [15] 
studied the catalytic steam reforming of two simulated aqueous fractions in a fixed bed reactor. The first aqueous fraction consisted of a mixture of equal amounts of methanol, ethanol, acetic acid, and acetone (light fraction), while the second was made up of equal amounts of furfural, phenol, catechol and m-cresol (heavy fraction). High $\mathrm{H}_{2}$ yield and carbon conversion to gas were obtained at a relatively low temperature $\left(650^{\circ} \mathrm{C}\right)$ during the steam reforming of the light fraction. However, a higher temperature $\left(800^{\circ} \mathrm{C}\right)$ was necessary to obtain the same $\mathrm{H}_{2}$ yield and carbon conversion to gas with the heavy fraction. To achieve efficient steam reforming at $800^{\circ} \mathrm{C}$, the heavy fraction required a higher S/C ratio (10) than that of the light fraction (7). For the same carbon space velocity, the drop in the $\mathrm{H}_{2}$ yield and in the carbon conversion to gas was higher for the heavy fraction than for the light fraction. Carbon deposition in the steam reforming of the heavy fraction was much more severe than for the light fraction, as determined by carbon content analysis and SEM detection. Bimbela et al. [16] compared the catalytic steam reforming of a simulated mixture of acetic acid, acetol and butanol with the results obtained for a real aqueous fraction of bio-oil using a Ni-based catalyst. The synthetic aqueous fraction provided both complete and steady carbon conversion to gas and a hydrogen yield close to that determined by the thermodynamic equilibrium. In contrast, a lower carbon conversion to gas and a lower hydrogen yield, which decreased with time as a result of the deactivation of the catalyst, were obtained with the real fraction.

The third approach uses real bio-oils or aqueous fractions in the reforming experiments. In general the reactivity of a given model compound is different when incorporated into a mixture as compared to its own conversion, since different interactions between biooil components can take place during the reforming process [17]. The use of real 
aqueous fractions allows all the possible interactions of all the compounds in the process to be taken into account. Consequently, this is the most realistic option for studying the influence of the chemical composition on the process. Real aqueous fractions obtained from pine, poplar, sawdust and beech wood feedstock have been used in several works $[5,18-23]$. These works focused on studying operating conditions, developing suitable catalysts and testing different reactors. Conversion of bio-oil of around $100 \%$ and $\mathrm{H}_{2}$ yields between 60 and $100 \%$ were achieved in these works. The temperature needed for full conversion ranged between 600 and $800{ }^{\circ} \mathrm{C}$, depending on the other operating conditions. The reactors used were fixed bed with trickle flow or liquid spray injection and fluidised beds. The stability of the catalyst was also studied, and in most cases the catalysts deactivated fast due to the formation of carbon deposition. Fluidised beds were more suited for the SR of bio-oil as the stability is higher for these reactors.

However, the vast majority of the works dealing with simulated or real bio-oils and/aqueous fractions focused more on developing suitable catalysts and on studying the effect of the operating conditions on the process than on understanding the effect of the chemical composition on the reforming process. Additionally, works focused on studying the effect of the chemical composition are scarce, and the use of different reactors, catalysts and operating conditions makes the comparison between bio-oil constituents difficult and in some cases unreliable.

Given this background, the present work examines the catalytic steam reforming of several aqueous fractions focusing on their chemical composition. The fractions were 
prepared from bio-oils obtained from pine and poplar sawdust whose pyrolysis step took place in two different experimental installations, aiming to produce bio-oils with different chemical compositions. To evaluate how and to what extent the chemical composition of the aqueous fractions affects the process, the aqueous fractions obtained from the bio-oils were prepared with the same water to carbon $(\mathrm{W} / \mathrm{C})$ ratio and the same operating conditions were used in the steam reforming experiments.

Different statistical methodologies have been used to correlate the results of the catalytic steam reforming experiments with the chemical composition of the aqueous fractions using the Bayesian Information Criterion (BIC). This strategy has permitted the identification of the chemical compounds and interactions with the highest probability of being responsible for the different behaviour of the aqueous fractions when catalytically reformed. The analysis of the results allowed the compounds responsible for the different reactivity and coke formation of the aqueous fractions to be identified. Additional experiments with some compounds alone (acetic acid, phenol, furfural, levoglucosan and guaiacol) were conducted in order to corroborate the results obtained. This strategy has never been used for studying the reactivity of bio-oil components. Taking into account that the effect of the bio-oil composition on the process has not been studied in depth and is not yet completely understood, this work represents a novel investigation in the field of $\mathrm{H}_{2}$ production from bio-oil.

\section{Materials and methods}

\subsection{Aqueous fractions preparation and characterisation}


The bio-oils used to prepare the aqueous fractions were obtained from the fast pyrolysis of pine or poplar sawdust at $490^{\circ} \mathrm{C}$. Two bio-oils were obtained from pine sawdust, one using a fluidised bed and the other using a spouted bed reactor. The other two bio-oils were obtained from poplar sawdust, one in each pyrolysis reactor.

To evaluate the influence of the specific chemical composition on the steam reforming process, aqueous fractions with the same water to carbon ratio $\left(\mathrm{W} / \mathrm{C}=7.6 \mathrm{~mol} \mathrm{H} \mathrm{H}_{2} \mathrm{O} / \mathrm{mol}\right.$ C) were prepared from the four different bio-oils. These aqueous fractions had a similar empirical formula for the organics and similar water content, but their chemical composition was different.

An aqueous fraction was prepared from each bio-oil. These were obtained by adding the bio-oil to water at a 1:2 weight ratio, respectively, using a similar method to that described by Sipillä et al. [3]. In the present work, two steps were employed. Firstly, taking into account the elemental analysis of the bio-oils, water was added until the theoretical $\mathrm{W} / \mathrm{C}$ ratio of $5.5 \mathrm{~mol} \mathrm{H}_{2} \mathrm{O} / \mathrm{mol} \mathrm{C}$ was reached. This water addition produced the precipitation of the water-insoluble lignin derivatives. Secondly, the precipitate was filtered and the aqueous fraction was then characterised. Finally, the aqueous fractions were diluted with more water in order to obtain the theoretical $\mathrm{W} / \mathrm{C}$ ratio of $7.6 \mathrm{~mol}$ $\mathrm{H}_{2} \mathrm{O} / \mathrm{mol} \mathrm{C}$. No additional phase separation was observed. Accordingly, a steam to carbon molar ratio $(\mathrm{S} / \mathrm{C})$ of $7.6 \mathrm{~mol} \mathrm{H}_{2} \mathrm{O} / \mathrm{mol} \mathrm{C}$ was used in the reforming experiments. This value for the steam to carbon ratio has commonly been used in works dealing with the catalytic steam reforming of bio-oil [5]. It implies an excess of water, which is beneficial for shifting the WGS equilibrium towards $\mathrm{H}_{2}$ production and also helps the 
gasification of the possible carbonaceous deposits on the catalyst surface. More information about this procedure can be found in our previous communication[22].

The aqueous fractions were analysed by gas chromatography using an Agilent GC 6890N apparatus fitted with a 5975 mass spectrometer detector (GC/MS). This experimental characterisation method is fully described in our previous communication [22]. The water content of the aqueous fractions was determined by the Karl Fisher titration method using a Mettler Toledo V20 volumetric titrator.

The elemental analyses were measured with an analyser using a complete oxidation method. Oxygen was determined by percentage difference.

\subsection{Experimental system and operating conditions}

The catalytic steam reforming experiments were carried out in a small bench scale test facility consisting of a fixed bed of $25 \mathrm{~mm}$ in height, placed inside a tubular quartz reactor of $9 \mathrm{~mm}$ inner diameter. The aqueous fraction was fed into the reactor with a HPLC pump. $\mathrm{N}_{2}$ was used as a carrier gas to facilitate the feeding of the aqueous fraction, as well as an internal standard for quantification purposes. Once inside the reactor, the vaporised aqueous fraction down-flow passed through the catalytic bed, consisting of a mixture of catalyst and inert sand, where the steam reforming reaction took place. The gaseous mixture passed to a condensation system consisting of a stainless steel vessel cooled by means of a Peltier thermoelectric cell where the condensable vapours were trapped. The permanent gases exiting the condensation system were analysed online with a micro gas chromatograph equipped with thermal conductivity detectors. More details concerning the set-up can be found in our previous communications $[22,23]$. 
Two different sets of experiments comprise the experimental part of this work. Firstly, experiments feeding the four aqueous fractions were conducted. These experiments were used to find the compounds responsible for the different results obtained during the reforming of the aqueous fractions. Secondly experiments with model compounds were carried out. Acetic acid, phenol, furfural, levoglucosan and guaiacol were chosen as model compounds. The same steam to carbon $(\mathrm{S} / \mathrm{C})$ ratio, $12 \mathrm{~mol} \mathrm{H}_{2} \mathrm{O} / \mathrm{mol} \mathrm{C}$, was used during the reforming of the model compounds. This ratio is slightly higher than that employed for the aqueous fractions $\left(\mathrm{S} / \mathrm{C}=7.6 \mathrm{~mol} \mathrm{H}_{2} \mathrm{O} / \mathrm{mol} \mathrm{C}\right)$ due to the low solubility in water of furfural.

All these experiments were carried out at a temperature of $650{ }^{\circ} \mathrm{C}$ and atmospheric pressure during $2 \mathrm{~h}$, employing a spatial time, defined as the mass of catalyst/organics flow rate ratio $\left(\mathrm{W} / \mathrm{m}_{\mathrm{org}}\right)$, of $4 \mathrm{~g}$ catalyst $\mathrm{min} / \mathrm{g}$ organics.

A Ni-Co/Al-Mg catalyst, which has been proved to be suitable for the catalytic steam reforming of bio-oil aqueous fractions $[22,23]$, was selected for this work. This catalyst includes $\mathrm{Ni}$ as the active phase. Ni based catalysts meet the challenge of being active and selective towards $\mathrm{H}_{2}$, although they are susceptible to deactivation by coking. Therefore, the catalyst was modified with $\mathrm{Mg}$ and $\mathrm{Co} . \mathrm{Mg}$ was added as a support modifier enhancing the water adsorption in order to gasify the coke or its precursors, as well as to provide more attrition resistance if the catalyst is to be used in a fluidised bed. Co was added as a active phase modifier to enhance the steam reforming and WGS 
reactions and prevent catalyst deactivation by coking, as a Ni-Co interaction can be formed in the catalyst which reduces the crystallite size [23].

The catalyst was prepared by coprecipitation, having $28 \%$ (relative atomic percentage) $\mathrm{Ni}$ expressed as $\mathrm{Ni} /(\mathrm{Ni}+\mathrm{Al}+\mathrm{Mg}+\mathrm{Co})$, a $\mathrm{Mg} / \mathrm{Al}$ atomic ratio of 0.26 and a $\mathrm{Co} / \mathrm{Ni}$ atomic ratio of 0.10 [23]. Crystalline phases of $\mathrm{NiO} / \mathrm{MgO}$ and $\mathrm{NiAl}_{2} \mathrm{O}_{4} / \mathrm{MgAl}_{2} \mathrm{O}_{4}$ spinels were found in the X-ray diffraction (XRD) analysis of the calcined precursor. No crystalline phases of Co were detected. These crystalline phases are in agreement with the TPR analyses, where two peaks were detected. A small peak was found at $300-320^{\circ} \mathrm{C}$, corresponding to the reduction of the $\mathrm{NiO}$ phase as well as the reduction of the $\mathrm{Co}_{3} \mathrm{O}_{4}$ phase [24-26]. This may suggest a high Ni-Co interaction, which was confirmed by the positive shift of the binding energy of $\mathrm{Ni} 2 \mathrm{p}_{3 / 2}$ detected in the XPS analysis. A second higher intensity peak was found at $732{ }^{\circ} \mathrm{C}$, which might correspond to the reduction of the $\mathrm{NiAl}_{2} \mathrm{O}_{4}$ spinel phase. The BET surface area of the catalyst was about $132 \mathrm{~m} / \mathrm{g}$. Further information about the characterisation can be found in our previous communication [23].

\subsection{Experimental data processing}

\subsubsection{Response variables studied}

Different response variables were used to compare the reforming process of the aqueous fractions and the model compounds. The initial and overall $2 \mathrm{~h}$ carbon conversion to gas (CC gas, \%), and the initial and overall $2 \mathrm{~h} \mathrm{H}_{2}$ and $\mathrm{CO}_{2}$ yields (g/g organics) obtained during the catalytic steam reforming were compared in the experiments. To evaluate the tendency of the aqueous fractions and the model compounds to deactivate the catalyst, the loss, numerically calculated, in carbon conversion to gas and the loss in the $\mathrm{H}_{2}$ and 
$\mathrm{CO}_{2}$ yields, defined as the difference between the initial value and the final value obtained after $2 \mathrm{~h}$ of experiment (\%), were also compared. The liquid condensates were also analysed to calculate and compare the overall carbon conversion to liquid (CC liq, $\%)$ and the global conversion (X, \%) of the different compounds that constitute the aqueous fractions. The carbon conversion to solid (CC sol, \%) was calculated by difference and included both the carbon deposited on the catalyst (CC coke, \%) and the carbon resulting from an incomplete vaporisation of the feed (CC char, \%). The used catalyst was characterised by elemental analysis to calculate the amount of carbon deposited on the catalyst surface. The $\mathrm{CC}$ coke and the amount of $\mathrm{C}$ deposited $(\mathrm{mg} \mathrm{C} / \mathrm{g}$ catalyst g organic reacted) were calculated from these analyses. CC to char was therefore calculated by difference. Table 1 summarises the response variables used and the analytical methods employed for their calculation. 
Table 1. Response variables used for analysing the reforming results. Definitions and analytical techniques used in their determination.

\begin{tabular}{|c|c|c|}
\hline Product & Response variable & Analytical method \\
\hline \multirow{2}{*}{ Gas } & $\mathrm{CC}$ gas $(\%)=\frac{\mathrm{C} \text { in the gas }(\mathrm{g})}{\mathrm{C} \text { fed }(\mathrm{g})} 100$ & Micro Gas Chromatograph (Micro GC) \\
\hline & yield to i $\left(\frac{\mathrm{g} \mathrm{i}}{\mathrm{g} \text { organics }}\right)=\frac{\text { mass of } \mathrm{i}(\mathrm{g})}{\text { mass of organics fed }(\mathrm{g})}$ & Online analyses \\
\hline \multirow{5}{*}{ Liquid } & CC liq $(\%)=\frac{\mathrm{C} \text { in the liquid }(\mathrm{g})}{\mathrm{C} \text { fed }(\mathrm{g})} 100$ & $\begin{array}{c}\text { Total Organic Carbon (TOC). } \\
\text { GC-MS (Gas Chromatography-Mass }\end{array}$ \\
\hline & \multirow{4}{*}{$\mathrm{Xi}(\%)=\frac{\mathrm{i} \text { fed }(\mathrm{g})-\mathrm{i} \text { in the liquid phase }(\mathrm{g})}{\mathrm{i} \text { fed }(\mathrm{g})} 100$} & Spectroscopy). \\
\hline & & GC-FID (Gas Chromatography-Flame \\
\hline & & ionization detector) \\
\hline & & Offline analyses \\
\hline \multirow{5}{*}{ Solid } & CC sol $(\%)=100-$ CC gas (\%) - CC liq(\%) & \\
\hline & \multirow[t]{2}{*}{$\mathrm{CC}$ coke $(\%)=\frac{\mathrm{C} \text { on the catalyst }(\mathrm{g})}{\mathrm{C} \text { fed }(\mathrm{g})} 100$} & Elemental Analysis. \\
\hline & & Offline analysis \\
\hline & \multicolumn{2}{|l|}{ CC char $(\%)=\mathrm{CC}$ sol $(\%)-\mathrm{CC}$ coke $(\%)$} \\
\hline & $\mathrm{C}(\mathrm{mg} / \mathrm{g}$ catalyst $\mathrm{g}$ org $)=\frac{\mathrm{C} \text { deposited on catalyst }(\mathrm{g}) * 1000}{\mathrm{~g} \text { organics reacted }}$ & \\
\hline
\end{tabular}

\subsubsection{Statistical analyses}

One-way analysis of variance (one-way ANOVA) was used to compare the results obtained with the aqueous fractions and/or the model compounds. The results of the statistical analyses are presented in the form of p-values. For any comparison, if the pvalue obtained is lower than the significance level used in this work $(\alpha=0.05)$, it can be concluded with $95 \%$ confidence that there are statistically significant differences between the values that are being compared. When the ANOVA analysis detected significant differences, the multiple range Fisher's least significant difference (Fisher's LSD) test was employed to determine the differences between pairs of data. The results of this test are presented in the form of a multiple range classification, classifying the 
results in different homogeneous groups using as many letters as homogeneous groups. Results sharing the same letter belong to the same homogeneous group.

The information obtained from the reforming results of the four aqueous fractions was correlated to their different chemical compositions using statistical empirical models. Additive models with interactions were considered since the possible interactions between chemicals can significantly affect the reforming process [17]. The Bayesian Information Criterion (BIC) was used to choose the best model. The BIC is intended to help select the best model from among several competing models. A BIC value is calculated for each model under consideration, and the model with the smallest BIC value is chosen as the best. This model should strike a balance between fitting the data well and using only a few parameters, allowing the identification of the chemical compounds and interactions with the highest probability of being responsible for the different behaviour of the aqueous fractions when catalytically reformed [27, 28]. Given the empirical character of these models, their specific equations cannot be extrapolated but they are appropriate for identifying whether or not the variations observed in the steam reforming can be correlated to the variations in their chemical composition. Codec models, where factors are centred by mean and codec by range, were created from the real models. Codec models are useful for comparison purposes. In addition, the influence of each compound has been compared making use of the cause - effect Pareto Principle, where the influence of each term in the model is calculated. The higher the Pareto percentage of a compound in the model, the greater is its influence on the response variable.

\subsubsection{Theoretical calculations}


The theoretical equilibrium yields were calculated using Aspentech HYSYS 8.4 simulation software employing a Gibbs reactor module with the PRSV thermodynamic package. More information about this theoretical calculation can be found in our previous communication [23].

\section{Results and discussion}

\subsection{Aqueous fractions characterisation}

Table 2 shows the elemental analysis and the water content of the four aqueous fractions used in this work. The chemical analysis results, expressed as mg of compound/ $\mathrm{g}$ of sample, are listed in Table 3. The chemical composition of the four aqueous fractions has been compared using a statistical analysis of variance (ANOVA) with $95 \%$ confidence. The results of this test are also summarised in Table 3.

Table 2. Characteristics (raw basis) of the prepared $S / C=7.6$ aqueous fractions.

\begin{tabular}{ccccc}
\hline $\begin{array}{c}\text { Elemental } \\
\text { analysis } \\
(\mathbf{w t - \% )}\end{array}$ & $\begin{array}{c}\text { Fluidised bed } \\
\text { PINE }\end{array}$ & $\begin{array}{c}\text { Spouted bed } \\
\text { PINE }\end{array}$ & $\begin{array}{c}\text { Fluidised bed } \\
\text { POPLAR }\end{array}$ & $\begin{array}{c}\text { Spouted bed } \\
\text { POPLAR }\end{array}$ \\
\hline $\mathrm{C}$ & 7.35 & 7.36 & 7.53 & 7.28 \\
$\mathrm{H}$ & 10.58 & 10.61 & 11.08 & 10.95 \\
$\mathrm{O}^{\mathrm{a}}$ & 81.83 & 81.62 & 81.31 & 81.65 \\
$\mathrm{H}_{2} \mathrm{O}(\mathrm{wt}-\%)^{\mathrm{b}}$ & 83.69 & 81.44 & 85.88 & 83.03 \\
\hline $\begin{array}{l}\text { a-By difference. } \\
\text { b- Karl-Fischer analysis }\end{array}$ & & & \\
$\mathrm{H}$ and O values include water content. & &
\end{tabular}


Table 3. Chemical analysis ( $\mathrm{mg} / \mathrm{g}$ sample) of the prepared $\mathrm{S} / \mathrm{C}=7.6$ aqueous fractions. Results are expressed as mean \pm standard deviation.

\begin{tabular}{|c|c|c|c|c|c|}
\hline & \multicolumn{2}{|c|}{ PINE } & \multicolumn{2}{|c|}{ POPLAR } & \multirow[b]{2}{*}{ p-value } \\
\hline & $\begin{array}{c}\text { FLUIDISED } \\
\text { BED }\end{array}$ & $\begin{array}{c}\text { SPOUTED } \\
\text { BED } \\
\end{array}$ & $\begin{array}{c}\text { FLUIDISED } \\
\text { BED }\end{array}$ & $\begin{array}{c}\text { SPOUTED } \\
\text { BED }\end{array}$ & \\
\hline Carboxylic acids & $13.0 \pm 6.0^{B}$ & $11.0 \pm 4.0^{B}$ & $28.7 \pm 4.3^{A}$ & $27.5 \pm 4.8^{A}$ & 0.041 \\
\hline Formic acid & $5.1 \pm 2.8^{\mathrm{A}}$ & $4.0 \pm 3.9^{\mathrm{A}}$ & $4.7 \pm 3.6^{\mathrm{A}}$ & $4.7 \pm 3.6^{\mathrm{A}}$ & 0.988 \\
\hline Propionic acid & $0.5 \pm 0.1^{\mathrm{C}}$ & $0.9 \pm 0.1^{\mathrm{B}}$ & $1.2 \pm 0.1^{\mathrm{A} \mathrm{B}}$ & $1.3 \pm 0.1^{\mathrm{A}}$ & 0.007 \\
\hline $\begin{array}{l}\text { Alcohols } \\
\text { Methanol } \\
\end{array}$ & $3.0 \pm 1.2^{A}$ & $3.0 \pm 1.1^{A}$ & $6.0 \pm 1.6^{A}$ & $6.1 \pm 1.9^{A}$ & 0.172 \\
\hline Aldehydes & $58.3 \pm 42.9^{A}$ & $73.0 \pm 43.2^{A}$ & $61.9 \pm 22.0^{A}$ & $76.8 \pm 39.1^{A}$ & 0.951 \\
\hline Hydroxyacetaldehyde & $46.3 \pm 39.2^{\mathrm{A}}$ & $53.1 \pm 36.9^{\mathrm{A}}$ & $40.8 \pm 17.7^{\mathrm{A}}$ & $60.9 \pm 35.6^{\mathrm{A}}$ & 0.935 \\
\hline Acetaldehyde & $0.6 \pm 0.1^{\mathrm{A}}$ & $0.9 \pm 0.5^{\mathrm{A}}$ & $0.7 \pm 0.2^{\mathrm{A}}$ & $0.5 \pm 0.1^{\mathrm{A}}$ & 0.696 \\
\hline Formaldehyde & $3.7 \pm 0.3^{\mathrm{A} \mathrm{B}}$ & $5.0 \pm 0.5^{\mathrm{A}}$ & $2.2 \pm 0.9^{\mathrm{BC}}$ & $1.0 \pm 0.5^{\mathrm{C}}$ & 0.009 \\
\hline $\begin{array}{l}\text { Ketones } \\
\text { 2-Propanone,1-hydroxy- }\end{array}$ & $7.4 \pm 3.5^{\mathrm{A}}$ & $13.9 \pm 6.3^{A}$ & $17.5 \pm 3.5^{A}$ & $13.9 \pm 4.0^{A}$ & 0.345 \\
\hline Aromatics & $1.9 \pm 0.1^{A}$ & $1.6 \pm 0.1^{A}$ & $3.4 \pm 0.8^{A}$ & $2.8 \pm 1.0^{A}$ & 0.145 \\
\hline Phenols & $0.5 \pm 0.0^{\mathrm{B}}$ & $0.8 \pm 0.1^{\mathrm{B}}$ & $2.0 \pm 0.5^{\mathrm{A}}$ & $2.0 \pm 0.5^{\mathrm{A}}$ & 0.022 \\
\hline Guaiacols, syringols & $1.4 \pm 0.1^{\mathrm{A}}$ & $0.8 \pm 0.0^{\mathrm{A}}$ & $1.4 \pm 0.3^{\mathrm{A}}$ & $0.8 \pm 0.6^{\mathrm{A}}$ & 0.272 \\
\hline
\end{tabular}

A, B and C in each row represent statistically different homogeneous groups with $95 \%$ confidence

From the results shown in Table 2, it can be appreciated that there are no significant differences in terms of elemental analysis and water content between the aqueous fractions obtained from the four bio-oils. In contrast, the results in Table 3 show significant differences in terms of chemical composition. In the analyses, carboxylic acids (acetic acid, formic acid and propionic acid), alcohols (methanol), aldehydes (hydroxyacetaldehyde, acetaldehyde and formaldehyde), ketones (2-propanone, 1hydroxy), furans (furfural), sugars (levoglucosan) and aromatic compounds (phenols, guaiacols and syringols) were identified and quantified for the four aqueous fractions.

The results presented in Table 3 indicate that the pyrolysis unit and the source of biomass have a significant influence on the chemical composition of the aqueous fractions. This has been shown previously by Ayalur et al. [29]. Statistically significant differences in the concentrations of acetic acid, propionic acid, formaldehyde, furfural, 
levoglucosan and phenols were obtained in the aqueous fractions. It was found that for some compounds (acetic acid, formaldehyde and phenols) these variations depend only on the biomass source while for others (propionic acid, furfural and levoglucosan) they depend on both the biomass source and the pyrolysis unit employed in the pyrolysis step. More specifically, the aqueous fractions obtained from poplar have a statistically higher concentration of acetic acid and phenols and a lower concentration of formaldehyde and levoglucosan than the two aqueous fractions obtained from pine.

These differences are commonly related to the different amounts of cellulose, hemicellulose and lignin in the two biomasses. Pine biomass has an overall composition of 35 wt.\% cellulose, 29 wt.\% hemicellulose and 28 wt.\% lignin [30], while poplar biomass has 45 wt.\% cellulose, 17 wt.\% hemicellulose and $31 \mathrm{wt.} \%$ lignin [31]. The pyrolysis of cellulose consists of an initial depolymerisation to anhydrosugars, followed by a pyranose ring-breaking to light oxygenated species such as aldehydes. The pyrolysis of hemicellulose [31] consists of depolymerisation, dehydratation to furan and pyran ring derivatives and then furanose and pyranose ring-breakage to light oxygenated species such as acetic acid, among others. The pyrolysis of lignin comprises an initial transformation into alkyl phenols and the posterior formation of phenols, substituted phenols and other small oxygenated species.

The higher content of acetic acid and the lower amount of levoglucosan in the two poplar aqueous fractions compared to the two pine aqueous fractions do not fit the expected trends, considering the overall composition of pine and poplar reported in the literature [30,31]. These differences could be a consequence of a different composition 
in terms of cellulose, hemicellulose and lignin of the biomasses used in this work compared with the overall composition reported in the literature.

\subsection{Catalytic steam reforming of pine and poplar aqueous fractions}

This section discusses the results concerning the initial yields, the evolution of yields over time and the carbon deposited on the catalyst obtained during the reforming of the aqueous fractions.

\subsubsection{Initial yields}

Table 4 lists the initial catalytic steam reforming results (prior to catalyst deactivation) for the four aqueous fractions, including the initial carbon conversion to gas, the experimental initial $\mathrm{H}_{2}$ and $\mathrm{CO}_{2}$ yields, the equilibrium results, and the results obtained in the ANOVA analysis. These results show that the four aqueous fractions tested provide statistically different results when they are catalytically reformed under the same operating conditions. Significant differences were found $(p$-values $<0.05)$ for all the studied response variables.

The two aqueous fractions obtained from the pine bio-oils provided higher initial $\mathrm{H}_{2}$ yields than those obtained from the poplar bio-oils. No statistically significant differences were found between the two pine aqueous fractions in terms of initial $\mathrm{H}_{2}$ yield. In contrast, there were differences between the two poplar aqueous fractions. Statistically higher initial $\mathrm{H}_{2}$ yields were obtained for the aqueous fraction whose pyrolysis step took place in the fluidised bed than the fraction pyrolysed in the spouted 
bed. The initial $\mathrm{CO}_{2}$ yield was higher when reforming the aqueous fractions obtained from pine. Moreover, for the pine aqueous fractions, higher initial $\mathrm{CO}_{2}$ yields were obtained during the reforming of the aqueous fraction obtained in the spouted bed. In contrast, in the case of the poplar aqueous fractions a higher initial $\mathrm{CO}_{2}$ yield was reached during the reforming of the aqueous fraction whose pyrolysis took place in the fluidised bed installation. The initial carbon conversion to gas only depended on the biomass source. A higher (and almost complete) initial carbon conversion to gas was achieved in the steam reforming of the two pine aqueous fractions than in the reforming of the two poplar fractions. Given that the four aqueous fractions were prepared having the same $\mathrm{W} / \mathrm{C}$ ratio and that they have a very similar elemental composition, these results indicate that the chemical composition of the aqueous fraction of the bio-oil influences the steam reforming process.

Table 4. Results obtained in the steam reforming experiments: Initial carbon conversion to gas, initial gas yields, loss in the carbon conversion to gas and loss in the $\mathrm{H}_{2}$ and $\mathrm{CO}_{2}$ yields. Results are expressed as mean \pm standard deviation. Operating conditions: $t$ $=2 \mathrm{~h}, T=650{ }^{\circ} \mathrm{C}, P=1 \mathrm{~atm}, \mathrm{~S} / \mathrm{C}=7.6 \mathrm{~mol} / \mathrm{mol}$, Liquid flow rate $=0.12 \mathrm{~mL} / \mathrm{min}$, $\mathrm{W} / \mathrm{m}_{\text {org }}=4 \mathrm{~g}$ cat. $\mathrm{min} / \mathrm{g}$ org., $\mathrm{N}_{2}$ flow rate $=75 \mathrm{STP} \mathrm{mL} / \mathrm{min}$.

\begin{tabular}{|c|c|c|c|c|c|c|c|c|}
\hline Aqueous fractions & $\begin{array}{c}\text { Initial CC } \\
\text { gas (\%) }\end{array}$ & $\begin{array}{c}\text { Initial } \mathrm{H}_{2} \\
\text { yield } \\
\text { (g/g org.) }\end{array}$ & $\begin{array}{c}\text { Initial } \mathrm{CO}_{2} \\
\text { yield } \\
\text { (g/g org.) }\end{array}$ & $\begin{array}{c}\text { Initial CO } \\
\text { yield } \\
\text { (g/g org.) }\end{array}$ & $\begin{array}{c}\text { Initial } \mathrm{CH}_{4} \\
\text { yield } \\
\text { (g/g org.) }\end{array}$ & $\begin{array}{c}\text { Loss in CC } \\
\text { gas (\%) }\end{array}$ & $\begin{array}{l}\text { Loss in } \mathrm{H}_{2} \\
\text { yield }(\%)\end{array}$ & $\begin{array}{c}\text { Loss in } \mathrm{CO}_{2} \\
\text { yield (\%) }\end{array}$ \\
\hline Pine Fluidised Bed & $96.48 \pm 0.44^{\mathrm{a}}$ & $0.182 \pm 0.006^{\mathrm{a}}$ & $1.201 \pm 0.019^{\mathrm{b}}$ & $0.240 \pm 0.007^{\mathrm{a}}$ & $0.004 \pm 0.001^{\mathrm{a}}$ & $62.28 \pm 12.13^{\mathrm{a}}$ & $81.604 .78^{\mathrm{a}}$ & $76.37 \pm 3.68^{\mathrm{a}}$ \\
\hline Pine Spouted Bed & $92.04 \pm 10.99^{\mathrm{a}}$ & $0.180 \pm 0.012^{\mathrm{a}}$ & $1.280 \pm 0.000^{\mathrm{a}}$ & $0.223 \pm 0.007^{\mathrm{a}}$ & $0.004 \pm 0.001^{\mathrm{a}}$ & $63.07 \pm 2.62^{\mathrm{a}}$ & $80.10 \pm 8.03^{\mathrm{a}}$ & $77.91 \pm 8.48^{\mathrm{a}}$ \\
\hline Poplar Fluidised Bed & $60.11 \pm 0.87^{\mathrm{b}}$ & $0.129 \pm 0.003^{b}$ & $1.051 \pm 0.1065^{\mathrm{c}}$ & $0.083 \pm 0.007^{\mathrm{b}}$ & $0.00 \pm 0.00^{\mathrm{b}}$ & $29.33 \pm 6.58^{b}$ & $26.94 \pm 2.74^{b}$ & $46.40 \pm 7.24^{\mathrm{b}}$ \\
\hline Poplar Spouted Bed & $58.56 \pm 0.88^{\mathrm{b}}$ & $0.101 \pm 0.000^{\mathrm{c}}$ & $0.814 \pm 0.023^{\mathrm{d}}$ & $0.060 \pm 0.007^{b}$ & $0.00 \pm 0.00^{\mathrm{b}}$ & $14.28 \pm 1.30^{\mathrm{b}}$ & $31.03 \pm 1.29^{\mathrm{b}}$ & $34.78 \pm 4.39^{\mathrm{b}}$ \\
\hline Equilibrium & 100 & 0.170 & 1.440 & 0.150 & 0.0003 & 0 & 0 & 0 \\
\hline p-value & 0.0041 & 0.0007 & 0.0001 & 0.0001 & 0.0049 & 0.0051 & 0.0006 & 0.0052 \\
\hline
\end{tabular}

In order to identify the chemical compound/compounds or interactions between 
compounds responsible for the different performance of the aqueous fractions when catalytically reformed, empirical statistical models were developed to relate the steam reforming results of the four aqueous fractions with their specific chemical compositions. The concentrations of acetic acid, propionic acid, formaldehyde, furfural, levoglucosan, phenols and the binary interactions between these compounds were considered as inputs for these models since these were the chemical compounds whose concentrations were statistically different.

Table 5 shows the empirical models obtained and the Pareto influence of each factor for the initial carbon conversion to gas, the initial $\mathrm{H}_{2}$ yields and the initial $\mathrm{CO}_{2}$ yields as a function of the chemical composition of the four aqueous fractions tested. The concentration of phenol was not included in Table 5 as it was found to be insignificant for these models. For all the models, the lack of fit is not statistically significant in relation to the pure error with $95 \%$ confidence. Furthermore, their $\mathrm{R}^{2}$ is higher than 0.93 and very close to the maximum $\mathrm{R}^{2}$ that can be obtained with the experimental data of this work. This indicates that the models accurately describe the variations observed during the steam reforming of the aqueous fractions.

According to the statistical analysis, the different initial $\mathrm{H}_{2}$ yield in this work is a consequence of the different concentrations of acetic acid and furfural in the aqueous fractions. Taking into account the empirical models created for the initial $\mathrm{H}_{2}$ yield, an increase in the concentration of acetic acid leads to a decrease in the initial $\mathrm{H}_{2}$ yield. Moreover, furfural and the interaction between acetic acid and furfural have the opposite effect. Studying their relative influence, it was found from the Pareto analysis 
that the chemical with the highest influence on the initial $\mathrm{H}_{2}$ yield was acetic acid.

Table 5. Statistically significant models with $95 \%$ confidence obtained with the Bayesian Information Criterion (BIC) for the studied response variables.

\begin{tabular}{|c|c|c|c|c|c|c|c|c|c|c|c|}
\hline Response & $\begin{array}{c}\mathbf{R}^{2} / \\
\mathbf{R}^{2} \max \end{array}$ & $\begin{array}{l}\text { Model and } \\
\text { Influence }\end{array}$ & Intercept & $\begin{array}{l}\text { Acetic } \\
\text { Acid }\end{array}$ & $\begin{array}{l}\text { Propio- } \\
\text { nic Acid }\end{array}$ & $\begin{array}{c}\text { Formalde- } \\
\text { hyde }\end{array}$ & $\begin{array}{c}\text { Furfu- } \\
\text { ral }\end{array}$ & $\begin{array}{l}\text { Levo- } \\
\text { glucosan }\end{array}$ & $\begin{array}{l}\text { Acetic } \\
\text { Acid* } \\
\text { Furfural }\end{array}$ & $\begin{array}{c}\text { Ac. } \\
\text { Acid*Levo } \\
\text {-glucosan }\end{array}$ & $\begin{array}{l}\text { Formal- } \\
\text { dehyde * } \\
\text { Furfural }\end{array}$ \\
\hline \multirow{3}{*}{$\begin{array}{l}\text { Initial } \mathrm{H}_{2} \text { yield } \\
\text { (g/g org) }\end{array}$} & \multirow{3}{*}{$\begin{array}{l}0.976 / \\
0.980\end{array}$} & Actual & 0.155 & -0.0037 & ns & ns & 0.072 & ns & 0.008 & $\mathrm{~ns}$ & $\mathrm{~ns}$ \\
\hline & & Codec & 0.150 & -0.0340 & ns & ns & 0.023 & ns & 0.024 & ns & ns \\
\hline & & Pareto $(\%)$ & & 64 & 0 & 0 & 14 & 0 & 22 & 0 & 0 \\
\hline \multirow{3}{*}{$\begin{array}{l}\text { Initial } \mathrm{CO}_{2} \\
\text { yield (g/g org) }\end{array}$} & \multirow{3}{*}{$\begin{array}{l}0.995 / \\
0.996\end{array}$} & Actual & 0.552 & -0.0069 & ns & 0.0302 & 0.0791 & 0.0232 & ns & ns & -0.3318 \\
\hline & & Codec & 1.089 & -0.0634 & ns & 0.0697 & 0.0257 & 0.1690 & ns & ns & -0.2491 \\
\hline & & Pareto $(\%)$ & & 47 & 0 & 24 & 12 & 2 & 0 & 0 & 14 \\
\hline \multirow{3}{*}{$\begin{array}{l}\text { Initial Carbon } \\
\text { Conversion } \\
(\%) \\
\end{array}$} & \multirow{3}{*}{$\begin{array}{l}0.935 / \\
0.953\end{array}$} & Actual & 117.79 & -1.60 & -18.50 & $\mathrm{~ns}$ & Ns & ns & ns & ns & ns \\
\hline & & Codec & 76.80 & -14.64 & -8.23 & ns & Ns & ns & ns & ns & ns \\
\hline & & Pareto $(\%)$ & & na & na & 0 & 0 & 0 & 0 & 0 & 0 \\
\hline \multirow{3}{*}{$\begin{array}{l}\text { Loss } \mathrm{H}_{2} \text { yield } \\
(\%)\end{array}$} & \multirow{3}{*}{$\begin{array}{l}0.975 / \\
0.982\end{array}$} & Actual & 71.33 & -2.15 & ns & ns & Ns & 1.73 & ns & 0.18 & ns \\
\hline & & Codec & 61.98 & -19.67 & ns & ns & Ns & 12.61 & ns & 12.04 & ns \\
\hline & & Pareto $(\%)$ & & 82 & 0 & 0 & 0 & 9 & 0 & 9 & 0 \\
\hline \multirow{3}{*}{$\begin{array}{l}\text { Loss } \mathrm{CO}_{2} \text { yield } \\
(\%)\end{array}$} & \multirow{3}{*}{$\begin{array}{l}0.942 / \\
0.947\end{array}$} & Actual & 69.82 & -2.13 & ns & ns & 30.81 & ns & 3.88 & ns & ns \\
\hline & & Codec & 59.98 & -19.45 & ns & ns & 10.01 & ns & 11.55 & ns & ns \\
\hline & & Pareto $(\%)$ & & 70 & 0 & 0 & 10 & 0 & 20 & 0 & 0 \\
\hline \multirow{3}{*}{$\begin{array}{l}\text { Loss Carbon } \\
\text { Conversion } \\
(\%) \\
\end{array}$} & \multirow{3}{*}{$\begin{array}{l}0.943 / \\
0.947\end{array}$} & Actual & 51.18 & -2.35 & ns & ns & 38.87 & ns & 4.70 & ns & ns \\
\hline & & Codec & 43.59 & -21.51 & ns & ns & 12.63 & ns & 13.97 & ns & ns \\
\hline & & Pareto $(\%)$ & & 67 & 0 & 0 & 11 & 0 & 21 & 0 & 0 \\
\hline
\end{tabular}

ns Not significant with $95 \%$ confidence

${ }^{\text {na }}$ Not analysed

Actual model: Response $=$ Intercept + Acetic Acid coefficient $*$ [Acetic Acid] + Propionic Acid coefficient [Propionic Acid] + Formaldehyde coefficient * [Formaldehyde] + Furfural coefficient * [Furfural] + Levoglucosan * [Levoglucosan] + Acetic Acid * Furfural coefficient * [Acetic Acid] $*$ [Furfural] + Acetic Acid * Levoglucosan coefficient * [Acetic Acid] * [Levoglucosan]+ Formaldehyde * Furfural coefficient * [Formaldehyde] * [Furfural]

Codec model: factors centred by mean, scaled by range/2

Pareto values represent the percentage of the orthogonal estimate total value

The initial $\mathrm{CO}_{2}$ yield statistically depended on the concentration of acetic acid,

formaldehyde, furfural, levoglucosan and the interaction between formaldehyde and furfural. An increase in the concentration of acetic acid also leads to a decrease in the initial $\mathrm{CO}_{2}$ yield. Moreover, an increase in the concentration of formaldehyde, furfural and levoglucosan leads to an increase in the initial $\mathrm{CO}_{2}$ yield. An interaction between furfural and formaldehyde was detected. The Pareto analysis shows that acetic acid is again the compound with the greatest impact on the initial $\mathrm{CO}_{2}$ yield.

The initial carbon conversion to gas strongly depends on the concentration of acetic 
acid. An increase in the concentration of acetic acid decreases the $\mathrm{CC}$ gas.

These results are the consequence of two different effects. On the one hand, of all the compounds whose concentration was different in the aqueous fractions, acetic acid is the least reactive $[4,9]$. The main reason for its low reactivity is the high energy barrier needed for its reforming over Ni-based catalysts $(2.05 \mathrm{eV})[4]$. On the other hand, acetic acid is also the compound with the highest difference in concentration between the pine and poplar aqueous fractions.

Regarding the small differences between the aqueous fractions obtained from the same biomass, the slightly higher initial $\mathrm{H}_{2}$ yield of the poplar fluidised bed aqueous fraction compared to the poplar spouted bed fraction might be a consequence of the higher concentration of furfural. This is also consistent with the work of Wang et al. [4] where furfural was proved to be very reactive for catalytic steam reforming over Ni based catalyst with a low energy barrier $(0.7 \mathrm{eV})$. It is also important to mention that with the same operating conditions and $\mathrm{S} / \mathrm{C}$ ratio, the reforming of furfural provides a higher thermodynamic yield than the reforming of acetic acid. The $\mathrm{H}_{2}$ yields for solutions of acetic acid and furfural, both with $\mathrm{S} / \mathrm{C}=7.6 \mathrm{~mol} \mathrm{H}_{2} \mathrm{O} / \mathrm{mol} \mathrm{C}$, were $0.126 \mathrm{~g} \mathrm{H}_{2} / \mathrm{g}$ acetic acid and $0.196 \mathrm{~g} \mathrm{H}_{2} / \mathrm{g}$ furfural, respectively.

Slight differences were found between the initial $\mathrm{CO}_{2}$ yields of the aqueous fractions obtained from the two pyrolysis installations, although this difference was higher between the two poplar fractions. This might be a consequence of the higher 
concentration of formaldehyde and furfural in the poplar fluidised bed fraction. Formaldehyde can rapidly decompose to $\mathrm{CO}_{2}$, while furfural is very reactive for steam reforming over Ni based catalyst. Under the operating conditions of this work, the thermodynamic yields to $\mathrm{CO}_{2}$ for water solutions of acetic acid, formaldehyde and furfural, all with a $\mathrm{S} / \mathrm{C}$ ratio of $7.6 \mathrm{~mol} \mathrm{H}_{2} \mathrm{O} / \mathrm{mol} \mathrm{C}$, were $1.292 \mathrm{~g} \mathrm{CO}_{2} / \mathrm{g}$ acetic acid, $1.292 \mathrm{~g} \mathrm{CO}_{2} / \mathrm{g}$ formaldehyde and $1.997 \mathrm{~g} \mathrm{CO}_{2} / \mathrm{g}$ furfural, respectively. The high reactivity of formaldehyde and furfural in the process, along with their relatively high thermodynamic yields to $\mathrm{CO}_{2}$, allowed high experimental yields to $\mathrm{CO}_{2}$ to be achieved.

\subsubsection{Time evolution of carbon conversion to gas and $\mathrm{H}_{2}$ and $\mathrm{CO}_{2}$ yields}

Fig. 1 shows the evolution over time of the carbon conversion to gas and the yields to $\mathrm{H}_{2}$ and $\mathrm{CO}_{2}$. A decrease over time was observed for these response variables. The progressive loss over time is a consequence of two developments, the progressive deactivation of the catalyst as well as the progressive accumulation of carbon deposits on the upper part of the reactor, which decrease the amount of carbon in the gas feed. The atomisation system is not as effective when the liquid comes into contact with solid particles, leading to bigger droplet sizes. Consequently, the evaporation takes places at lower heating rates. This enhances the formation of more carbonaceous deposits, augmenting the formation of char over time, which increases the $\mathrm{CC}$ sol [32]. This overall loss of activity was higher for the steam reforming of the aqueous fractions obtained from the pine bio-oils than for those obtained from the poplar bio-oils. 
a)

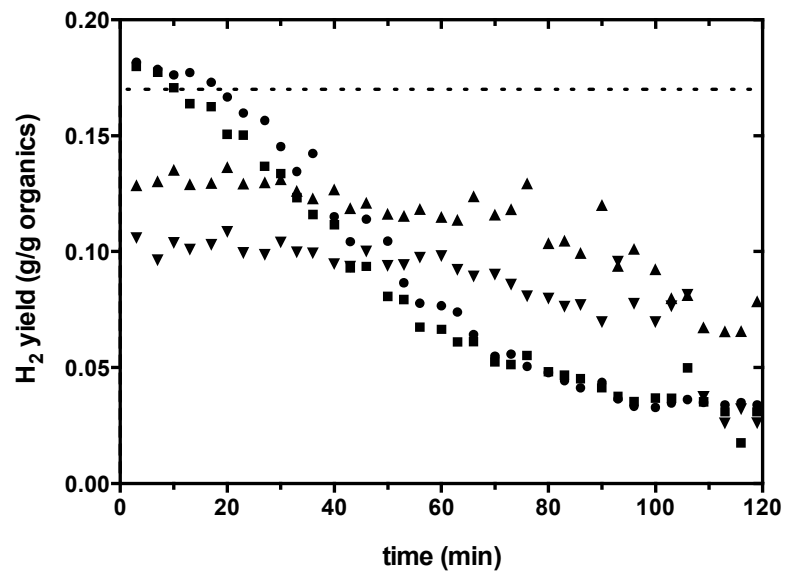

b)

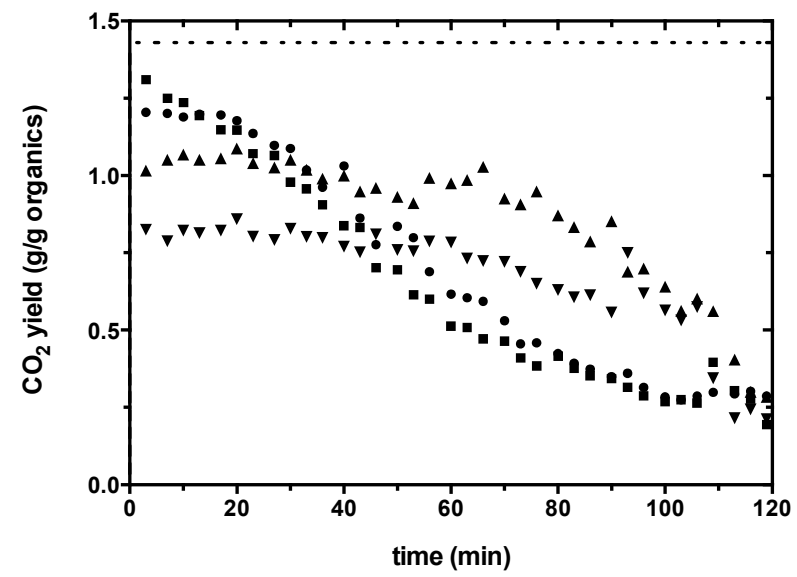

c)

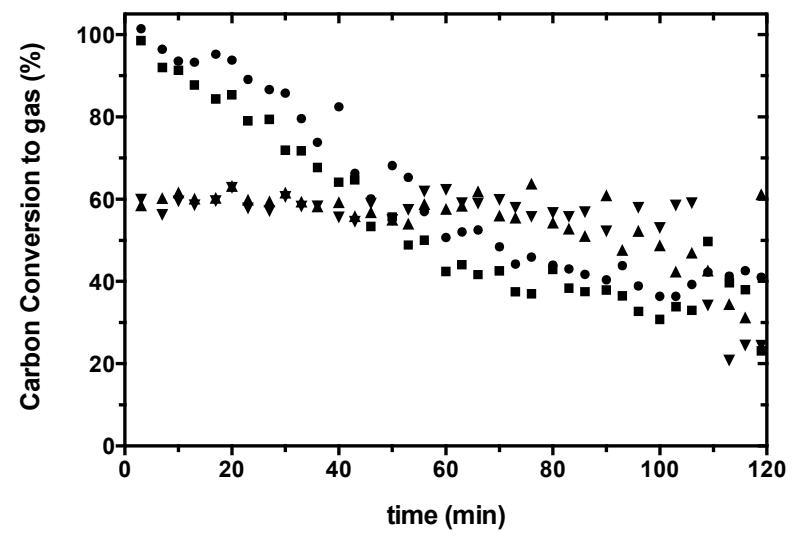

- Pine Fluidised Bed

A Poplar Fluidised Bed

- Pine Spouted Bed

$\nabla$ Poplar Spouted Bed

- Equilibrium

Fig. 1. Evolution with time of a) $\mathrm{H}_{2}$ yield, b) $\mathrm{CO}_{2}$ yield and c) Carbon conversion to gas for the four aqueous fractions. Operating conditions: $t=2 \mathrm{~h}, T=650^{\circ} \mathrm{C}, \mathrm{P}=1 \mathrm{~atm}$, $\mathrm{S} / \mathrm{C}=7.6 \mathrm{~mol} / \mathrm{mol}$, Liquid flow rate $=0.12 \mathrm{~mL} / \mathrm{min}, \mathrm{W} / \mathrm{m}_{\text {org }}=4 \mathrm{~g} \mathrm{cat}$. $\mathrm{min} / \mathrm{g}$ org., $N_{2}$ flow rate $=75 \mathrm{STP} \mathrm{mL} / \mathrm{min}$.

The loss of activity for the four aqueous fractions has been compared making use of an 
analysis of variance (ANOVA). The results of these calculations, as well as the results of the statistical analysis, are summarised in Table 4. From these results, it was found that the loss in carbon conversion and the loss in the yields to $\mathrm{H}_{2}$ and $\mathrm{CO}_{2}$ vary from 63 to $14 \%$, from 82 to $27 \%$, and from 78 to $35 \%$, respectively, depending on the aqueous fraction. The statistical analysis revealed that the loss in carbon conversion and the loss in the $\mathrm{H}_{2}$ and $\mathrm{CO}_{2}$ yields were statistically higher for the two pine aqueous fractions than for the two poplar ones. In addition, there were no statistically significant differences between the two pine aqueous fractions, or between the two poplar ones.

As before, the result for the loss of catalytic activity has been correlated with the chemical composition of the aqueous fractions using statistically empirical models created using the BIC criterion. These correlations are shown in Table 5.

The statistical analyses show that the loss in the $\mathrm{H}_{2}$ yield over time depended on the concentration of acetic acid and levoglucosan. The Pareto analysis and the empirical models show that acetic acid was the compound with the greatest influence on the loss of $\mathrm{H}_{2}$ activity. An increase in the concentration of acetic acid decreased the loss in the $\mathrm{H}_{2}$ yield.

Acetic acid exerts a different influence on the initial hydrogen yield than on the loss of this yield over time, which is calculated as the relative difference between the yield at the beginning and at the end of the experiment. On the one hand, acetic acid is not a very reactive compound, and the higher its concentration in the liquid fraction the lower the initial $\mathrm{H}_{2}$ yield obtained in the reforming. On the other hand, acetic acid has a low 
tendency to produce coke and consequently to deactivate the catalyst in comparison with other compounds studied in this work. Therefore, the higher the amount of acetic acid in the liquid, the lower the deactivation and the lower the loss of hydrogen yield.

This seems rather contradictory, since there are several works concerning the catalytic steam reforming of acetic acid over nickel-based catalyst [33, 34] where the catalyst suffers a progressive deactivation with time. This decrease in catalytic activity is related to the formation of coke during the reforming of acetic acid and its deposition on the catalyst due to the formation of coke precursor species such as $\mathrm{CH}^{*}$ and $\mathrm{CH}_{3} \mathrm{C}^{*}$ [4]. Medrano et al. [35] compared the $\mathrm{C}$ deposited on the catalyst of several oxygenated compounds, butanol, ethanol, acetol and acetic acid, in a fluidised bed reactor using a Ni-based catalyst. Acetic acid was found to be the compound with the highest coke formation. However, this comparison is relative and depends on the compounds being taken into account. In this work, acetic acid has been compared with other oxygenated compounds with a higher tendency to serve as coke precursors, such as furans and aromatic species [36].

\subsubsection{Overall reforming results}

In order to study the influence of the aqueous fractions on the overall reforming experiments, the overall carbon conversion to gas (\%), liquid (\%) and solid (\%) as well as the overall $\mathrm{H}_{2}$ and $\mathrm{CO}_{2}$ yields (g/g organics) over two hours have been calculated for each aqueous fraction. The results of these calculations are summarised in Table 6 . Furthermore, these overall results have been compared between the different aqueous fractions using an analysis of variance (ANOVA). The results of this test are also included in Table 6. 
Table 6. Overall 2-hours Carbon conversion to gas, liquid, solid, $\mathrm{H}_{2}$ and $\mathrm{CO}_{2}$ yields obtained during the steam reforming of the aqueous fractions. Results are expressed as mean \pm standard deviation. Operating conditions: $t=2 \mathrm{~h}, \mathrm{~T}=650^{\circ} \mathrm{C}, \mathrm{P}=1 \mathrm{~atm}, \mathrm{~S} / \mathrm{C}=$ $7.6 \mathrm{~mol} / \mathrm{mol}$, Liquid flow rate $=0.12 \mathrm{~mL} / \mathrm{min}, \mathrm{W} / \mathrm{m}_{\text {org }}=4 \mathrm{~g}$ cat. $\mathrm{min} / \mathrm{g}$ org., $N_{2}$ flow rate $=75 \mathrm{STP} \mathrm{mL} / \mathrm{min}$.

\begin{tabular}{lccccc}
\hline Aqueous fractions & CC gas (\%) & CC liq (\%) & CC sol (\%) & $\mathbf{H}_{2}$ yield (g/g organics) & CO $_{2}$ yield (g/g organics) \\
\hline Pine Fluidised Bed & $63.93 \pm 3.30^{\mathrm{a}}$ & $5.92^{\mathrm{a}}$ & $30.14^{\mathrm{a}}$ & $0.103 \pm 0.007^{\mathrm{a}}$ & $0.744 \pm 0.071^{\mathrm{b}}$ \\
Pine Spouted Bed & $60.68 \pm 2.80^{\mathrm{a}}$ & $10.65 \pm 0.68^{\mathrm{a}}$ & $28.66 \pm 2.22^{\mathrm{a}}$ & $0.100 \pm 0.007^{\mathrm{a}}$ & $0.716 \pm 0.006^{\mathrm{b}}$ \\
Poplar Fluidised Bed & $57.96 \pm 0.77^{\mathrm{a}}$ & $11.48 \pm 2.74^{\mathrm{a}}$ & $29.17 \pm 1.97^{\mathrm{a}}$ & $0.116 \pm 0.007^{\mathrm{a}}$ & $0.898 \pm 0.042^{\mathrm{a}}$ \\
Poplar Spouted Bed & $60.25 \pm 0.77^{\mathrm{a}}$ & $11.79 \pm 1.31^{\mathrm{a}}$ & $27.96 \pm 0.57^{\mathrm{a}}$ & $0.092 \pm 0.003^{\mathrm{a}}$ & $0.736 \pm 0.017^{\mathrm{b}}$ \\
p-value & 0.205 & 0.2128 & 0.5313 & 0.063 & 0.037
\end{tabular}

$\mathrm{a}$ and $\mathrm{b}$ in each column represent homogeneous groups. Levels not connected by the same letter are statistically different with $95 \%$ confidence

These results show that there are no great differences in the overall steam reforming of the four aqueous fractions tested in this work. More specifically, there were no statistically significant differences with $95 \%$ confidence in the overall-2-hour carbon conversion to gas, liquid and solid and the overall $\mathrm{H}_{2}$ yield. As an exception, a slightly higher overall $\mathrm{CO}_{2}$ yield was obtained for the aqueous fraction derived from poplar whose pyrolysis took place in the fluidised bed reactor. These results can be explained by considering the evolution with time of the carbon conversion to gas and the $\mathrm{H}_{2}$ and $\mathrm{CO}_{2}$ yields (Fig. 1). The higher initial values of the carbon conversion to gas and the $\mathrm{H}_{2}$ yield obtained for the pine aqueous fractions are compensated for by their higher deactivation. In contrast, while both lower initial carbon conversion to gas and $\mathrm{H}_{2}$ yields were obtained for the two aqueous fractions derived from poplar bio-oils, their lower deactivation makes it possible that the overall values would not be significantly different to those obtained for the aqueous fractions derived from pine. 
To gain a better insight into the catalytic steam reforming of the different organic compounds present in the aqueous fractions, the liquid condensates recovered in each experiment were analysed. The 2-hour overall CC liq and the two-hour overall conversions (for each compound) have been calculated. It should be pointed out that the conversion cannot be calculated with absolute accuracy because some of the initial components of the aqueous fractions such as methanol, acetone, phenol and alkylphenols are in turn products of the conversion of other components [17]. However, the concentration of the vast majority of the oxygenated compounds decreases significantly during the reforming process and a very accurate estimation of the conversion of the different organics can be calculated and used for comparison.

Table 7 shows the conversion of each compound for the four aqueous fractions tested in this work. Two different statistical analyses were conducted. Firstly, the conversions obtained during the reforming experiments of the four aqueous fractions were compared for each compound. From this comparison it was found that there were no statistically significant differences, with $95 \%$ confidence, between the conversions obtained of each one of the compounds during the reforming of the four aqueous fractions ( $\mathrm{p}$-values $>$ 0.05). This suggests that the reactivity of the studied compounds in the different mixtures is not different, with $95 \%$ confidence.

Secondly, another statistical analysis was conducted. This second analysis compares the individual conversion of each compound (in all the mixtures) with the conversion of the other chemicals (also in all the mixtures). This comparison allows the classification of the different chemicals into different groups according to their reactivity. Significant differences were detected with $95 \%$ confidence. The results of this test are also 
presented in Table 7 using different letters. Each letter represents a homogeneous group.

The reactivity of the organic compounds under the operating conditions tested is as follows: aldehydes (hydroxyacetaldehyde, acetaldehyde, formaldehyde) $=$ formic acid $=$ furfural $=$ levoglucosan $=$ guaiacols and syringols $>2$-propanone, 1-hydroxy $>$ methanol $>$ acetic acid $>$ phenols $>$ propionic acid

Table 7. Individual conversions for the different organic compounds present in the aqueous fractions. Results are expressed as mean \pm standard deviation.

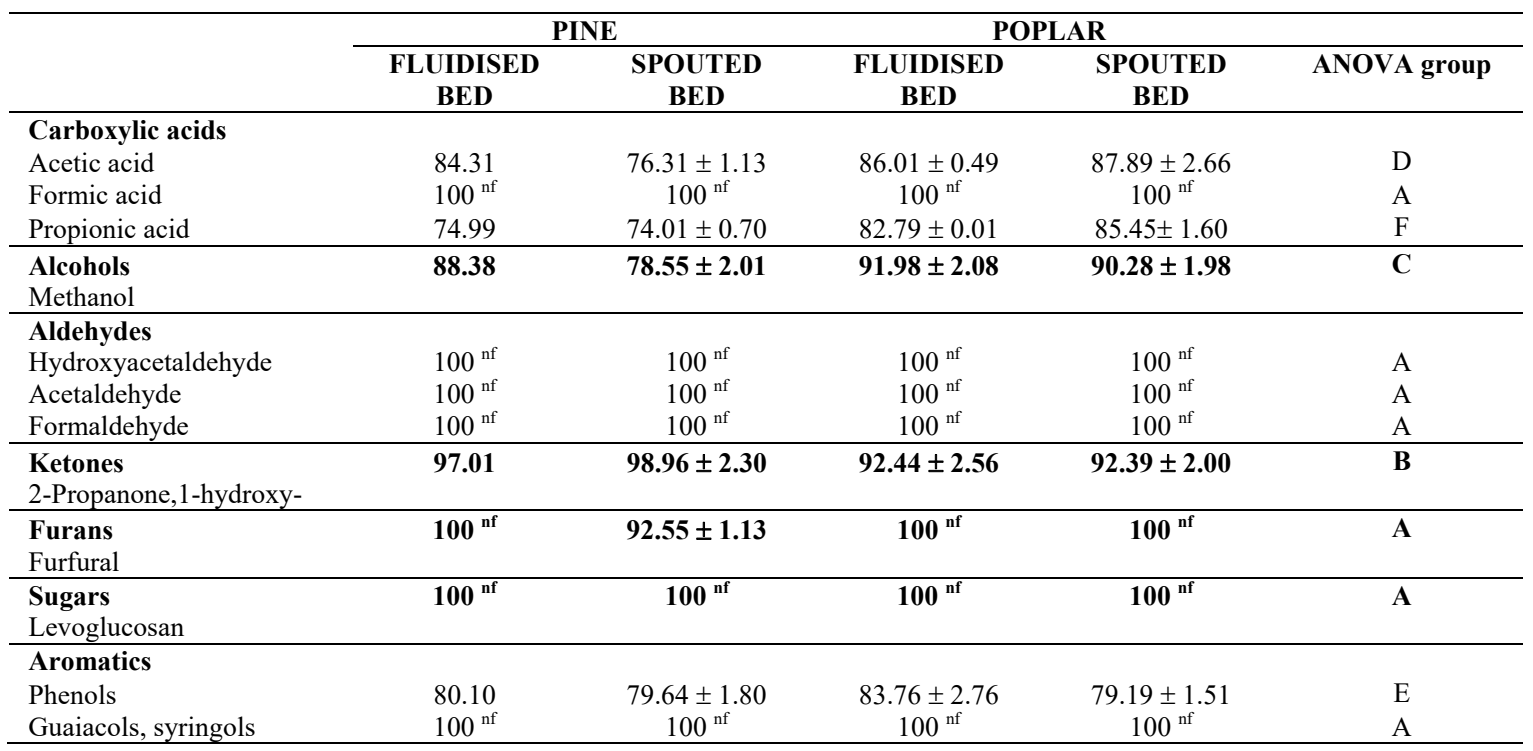

A, B, C, D, E and F represent statistically different homogeneous groups with $95 \%$ confidence

nf. Not found in the liquid condensate. Conversion assumed to be $100 \%$.

These results are in agreement with the results of Medrano et al. [8] and Bimbela et al. [7] (2-propanone-1 hydroxy > acetic acid), Wang et al. [1] (2-propanone-1 hydroxy > metanol $>$ acetic acid) and with the theoretical reactivity of some organic compounds developed in the work of Wang et al. [4] (furfural > 2-propanone-1 hydroxy $>$ acetic acid $>$ phenol). The different reactivity of these compounds is a consequence of the energy barriers of their different decompositions over Ni-based catalysts [4]. The lower 
initial conversion obtained during the reforming of the two poplar aqueous fractions compared with the two pine aqueous fractions is strongly related to their higher concentration of acetic acid.

\subsubsection{Coke deposition on the catalyst}

The loss of activity over time observed during the steam reforming experiments is mainly due to the deposition of coke on the catalyst surface. Elemental analyses were carried out on the used catalysts in order to quantify these carbon deposits. The amount of coke deposited on the catalysts during two hours of reaction, expressed as $\mathrm{mg} \mathrm{C} / \mathrm{g}$ catalyst g organics reacted [37], has been calculated and statistically compared. This comparison shows that the carbon content deposited on the catalyst was higher for the two aqueous fractions obtained from the bio-oils whose pyrolysis took place in the fluidised bed ( $155 \pm 28$ and $148 \pm 8 \mathrm{mg} \mathrm{C} / \mathrm{g}$ catalyst $\mathrm{g}$ organics reacted for the pine and the poplar, respectively) than for those whose pyrolysis was carried out in the spouted bed reactor $(96 \pm 12$ and $95 \pm 5 \mathrm{mg} \mathrm{C} / \mathrm{g}$ catalyst $\mathrm{g}$ organics reacted for the pine and the poplar, respectively). No significant differences in terms of coke deposition were found between the pine and poplar aqueous fractions when the bio-oils were produced in the same pyrolysis unit.

To elucidate which chemical compounds have the highest probability of being responsible for the different amounts of coke, Table 8 shows the results given by the empirical model developed to correlate the amount of coke with the concentration of the chemicals present in the aqueous fractions. The results suggest that the differences in the concentrations of formaldehyde, furfural and phenols between the aqueous fractions are the most plausible cause of the different amount of coke deposited on the catalyst. In 
addition, a significant interaction between formaldehyde and phenols was detected. Regarding the relative influence of each chemical on the coke formation, the Pareto analysis suggests that the compound with the highest influence in terms of carbon deposited on the catalyst during the reforming of the aqueous fractions is furfural, followed by phenols. This result is consistent with those given in the majority of studies on catalyst deactivation due to coke formation during the steam reforming of bio-oil $[17,30,36,38]$.

Table 8. Statistically significant model with $95 \%$ confidence obtained with the Bayesian Information Criterion (BIC) for the carbon deposited on the catalyst.

\begin{tabular}{lccccccc}
\hline Response & $\begin{array}{c}\mathbf{R}^{2} / \\
\mathbf{R}^{2} \mathbf{m a x}\end{array}$ & $\begin{array}{c}\text { Model and } \\
\text { Influence }\end{array}$ & Intercept & Formaldehyde & Furfural & Phenols & $\begin{array}{c}\text { Formaldehyde } \\
\text { * Phenols }\end{array}$ \\
\hline Carbon (mg & \multirow{2}{*}{$0.937 /$} & Actual & -16.10 & 9,75 & 139,89 & 23.06 \\
C/g cat g org) & 0.944 & Codec & 138.99 & 22.54 & 11.77 \\
& Pareto (\%) & & 10 & 45.46 & 21.56 \\
13 & 25.42 \\
\hline
\end{tabular}

Actual model: Response $=$ Intercept + Formaldehyde coefficient $*[$ Formaldehyde $]+$ Furfural coefficient $*[$ Furfural $]+$ Phenols coefficient * [Phenols] + Formaldehyde * Phenols coefficient * [Formaldehyde]* [Phenols]

Codec model: factors centred by mean, scaled by range/2

Pareto values represent the percentage of the orthogonal estimate total value

According to the statistical analyses, acetic acid was proposed as a key compound responsible for the differences found in terms of initial $\mathrm{CC}$ to gas, initial yields to $\mathrm{H}_{2}$ and $\mathrm{CO}_{2}$ and the evolution of these variables with time. However, it was not identified as a coke precursor. As stated above, furfural and, with less importance, phenols were the compounds responsible for the deposition of coke on the catalyst.

\subsection{Catalytic steam reforming of different model compounds}

Additional reforming experiments using solutions of model compounds in water were 
conducted in order to provide evidence for all the conclusions drawn from the results of the analysis of the bio-oil aqueous fractions. Of the chemicals present in the aqueous fractions, acetic acid, phenol, furfural and levoglucosan were chosen as model compounds, since they were responsible for the most important variations observed during the reforming of the fractions. In addition, experiments with guaiacol were also carried out in order to study its performance in the process.

\subsubsection{Thermodynamic results}

Table 9 shows the concentrations of the model compounds ( $\mathrm{mg} / \mathrm{g}$ sample) required to have $\mathrm{W} / \mathrm{C}$ ratios of $12 \mathrm{~mol} \mathrm{H}_{2} \mathrm{O} / \mathrm{mol} \mathrm{C}$, the reforming reactions and the thermodynamic $\mathrm{H}_{2}\left(\mathrm{~g} \mathrm{H}_{2} / \mathrm{g}\right.$ organic) and $\mathrm{CO}_{2}\left(\mathrm{~g} \mathrm{CO}_{2} / \mathrm{g}\right.$ organic $)$ yields under the reaction conditions. The thermodynamic $\mathrm{H}_{2}$ and $\mathrm{CO}_{2}$ yields are as follows: phenol> guaiacol > furfural > levoglucosan $>$ acetic acid. These results are in agreement with the statistical analysis results obtained from the reforming experiments of the aqueous fractions: an increase in the concentration of acetic acid decreased the initial $\mathrm{H}_{2}$ and $\mathrm{CO}_{2}$ yields, while an increase in the concentration of furfural augmented both the initial $\mathrm{H}_{2}$ and $\mathrm{CO}_{2}$ yields.

Table 9. Catalytic steam reforming of the model compounds. Initial concentrations in water $(\mathrm{g} / \mathrm{mL})$, reforming reactions and thermodynamic $\mathrm{H}_{2}\left(\mathrm{~g} \mathrm{H}_{2} / \mathrm{g}\right.$ organic) and $\mathrm{CO}_{2}(\mathrm{~g}$ $\mathrm{CO}_{2} / \mathrm{g}$ organic) yields at $650{ }^{\circ} \mathrm{C}$ and $1 \mathrm{~atm}$.

\begin{tabular}{|c|c|c|c|c|c|}
\hline Compound & $\begin{array}{c}\text { Concentration } \\
(\mathrm{mg} / \mathrm{g})\end{array}$ & Reforming reactions & $\begin{array}{c}\text { CC gas } \\
(\%)\end{array}$ & $\begin{array}{c}\mathrm{H}_{2} \text { yield } \\
\text { (g } \mathrm{H}_{2} / \mathrm{g} \text { org.) }\end{array}$ & $\begin{array}{c}\mathrm{CO}_{2} \text { yield } \\
\text { (g COO } / \text { g org.) }\end{array}$ \\
\hline Acetic Acid & 122 & $\mathrm{CH}_{3} \mathrm{COOH}+2 \mathrm{H}_{2} \mathrm{O} \rightarrow 2 \mathrm{CO}_{2}+4 \mathrm{H}_{2}$ & 100 & 0.13 & 1.35 \\
\hline Phenol & 68 & $\mathrm{C}_{6} \mathrm{H}_{5} \mathrm{OH}+11 \mathrm{H}_{2} \mathrm{O} \rightarrow 6 \mathrm{CO}_{2}+14 \mathrm{H}_{2}$ & 100 & 0.29 & 2.54 \\
\hline Furfural & 82 & $\mathrm{C}_{5} \mathrm{H}_{4} \mathrm{O}_{2}+8 \mathrm{H}_{2} \mathrm{O} \rightarrow 5 \mathrm{CO}_{2}+10 \mathrm{H}_{2}$ & 100 & 0.20 & 2.10 \\
\hline Guaiacol & 111 & $\mathrm{C}_{7} \mathrm{H}_{8} \mathrm{O}_{2}+12 \mathrm{H}_{2} \mathrm{O} \rightarrow 7 \mathrm{CO}_{2}+16 \mathrm{H}_{2}$ & 100 & 0.25 & 2.25 \\
\hline Levoglucosan & 76 & $\mathrm{C}_{6} \mathrm{H}_{10} \mathrm{O}_{5}+7 \mathrm{H}_{2} \mathrm{O} \rightarrow 6 \mathrm{CO}_{2}+12 \mathrm{H}_{2}$ & 100 & 0.14 & 1.50 \\
\hline
\end{tabular}




\subsubsection{Experimental steam reforming results}

Fig. 2 shows the evolution with time for the $\mathrm{CC}$ gas and the $\mathrm{H}_{2}$ and $\mathrm{CO}_{2}$ yields. Table 10 shows the overall $2 \mathrm{~h}$ results. These include the carbon conversion to gas, liquid and solid (CC gas, $\mathrm{CC}$ liq and $\mathrm{CC}$ sol), the global conversion (X), the global $\mathrm{H}_{2}$ and $\mathrm{CO}_{2}$ yields and the amount of carbon deposited on the catalyst expressed as $\mathrm{mg} \mathrm{C} / \mathrm{g}$ catalyst g organic reacted. The results for the different model compounds were compared using an analysis of variance (ANOVA) test with $95 \%$ confidence.

According to Fig. 2, the initial CC to gas for the different model compounds is as follows: acetic acid $=$ phenol $=$ furfural $>$ guaiacol $>$ levoglucosan. It can be seen that when acetic acid and phenol are reformed alone, a very high initial carbon conversion to gas is achieved (95\%). Furthermore, they also show a steady evolution with time (Loss in $\mathrm{CC}$ gas, $\mathrm{H}_{2}$ and $\mathrm{CO}_{2}$ yield $=0 \%$ ). This makes possible a complete global conversion for both compounds ( $>99 \%$ ), as can be seen from the results shown in Table 10 . 
a)

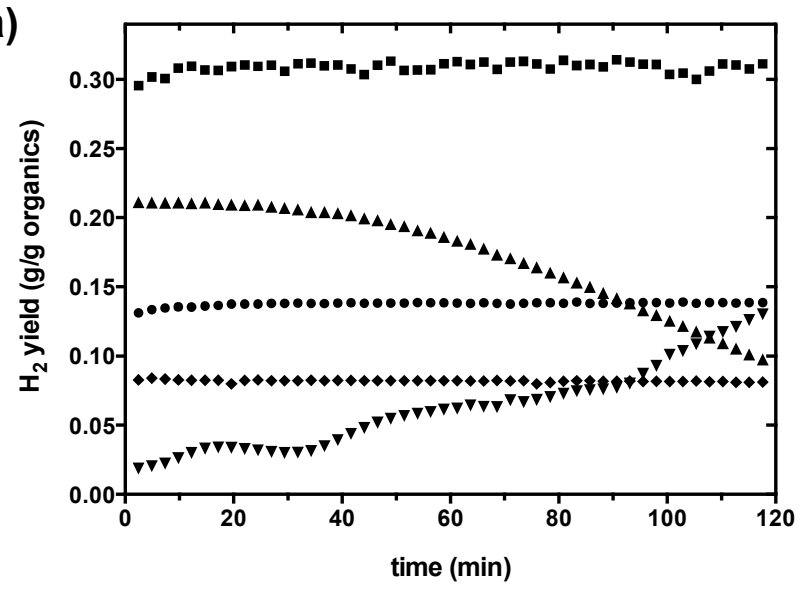

b)

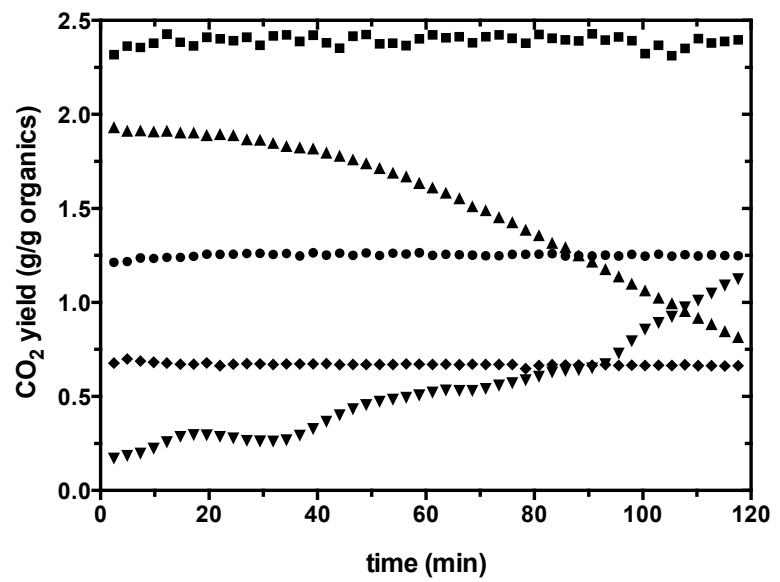

c)

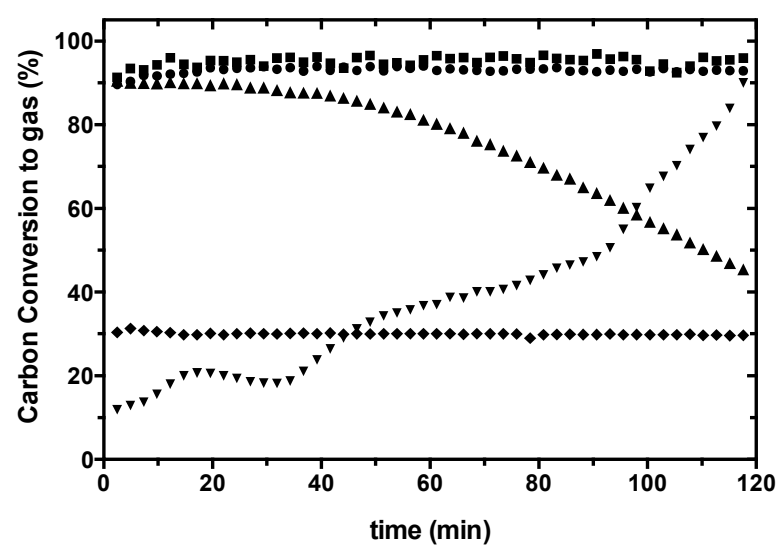

- Acetic Acid $\Delta$ Furfural Vevoglucosan

- Phenol Guaiacol

Fig. 2. Evolution with time of a) $\mathrm{H}_{2}$ yield, b) $\mathrm{CO}_{2}$ yield and c) Carbon conversion to gas for reforming of acetic acid, phenol, furfural, guaiacol and levoglucosan. Operating conditions: $t=2 \mathrm{~h}, T=650^{\circ} \mathrm{C}, P=1 \mathrm{~atm}, \mathrm{~S} / \mathrm{C}=12 \mathrm{~mol} / \mathrm{mol}$, Liquid flow rate $=0.12$ $\mathrm{mL} / \mathrm{min}, \mathrm{W} / \mathrm{m}_{\text {org }}=4 \mathrm{~g}$ cat. $\mathrm{min} / \mathrm{g}$ org., $N_{2}$ flow rate $=75 \mathrm{STP} \mathrm{mL} / \mathrm{min}$. 
Table 10. Overall 2-hours Carbon conversion to gas, liquid, solid (coke and char), $C$ deposited on the catalyst ( $\mathrm{mg} \mathrm{C} / \mathrm{g}$ catalyst $\mathrm{g}$ organic reacted), $\mathrm{H}_{2}$ and $\mathrm{CO}_{2}$ yields and the global conversion (X) obtained during the steam reforming of the model compounds. Results are expressed as mean \pm standard deviation. Operating conditions: $t=2 \mathrm{~h}, T=650^{\circ} \mathrm{C}, P=1 \mathrm{~atm}, \mathrm{~S} / \mathrm{C}=12 \mathrm{~mol} / \mathrm{mol}$, Liquid flow rate $=0.12 \mathrm{~mL} / \mathrm{min}$, $\mathrm{W} / \mathrm{m}_{\text {org }}=4 \mathrm{~g}$ cat. $\mathrm{min} / \mathrm{g}$ org., $N_{2}$ flow rate $=75 \mathrm{STP} \mathrm{mL} / \mathrm{min}$.

\begin{tabular}{|c|c|c|c|c|c|c|}
\hline & Acetic acid & Phenol & Furfural & Guaiacol & Levoglucosan & p-value \\
\hline CC to gas (\%) & $94.79 \pm 0.73^{\mathrm{a}}$ & $96.94 \pm 1.11^{\mathrm{a}}$ & $76.89 \pm 8.77^{b}$ & $28.93 \pm 1.00^{c}$ & $40.20 \pm 4.46^{\mathrm{c}}$ & 0.0004 \\
\hline CC to liquid (\%) & $0.04 \pm 0.007^{b}$ & $0.10 \pm 0.03^{b}$ & $8.56 \pm 2.33^{\mathrm{a}}$ & $0.03 \pm 0.00^{b}$ & $0.01 \pm 0.00^{b}$ & 0.0062 \\
\hline CC to solid (\%) & $5.18 \pm 0.74^{\mathrm{d}}$ & $3.01 \pm 1.08^{\mathrm{d}}$ & $18.62 \pm 0.69^{\mathrm{c}}$ & $71.84 \pm 0.99^{\mathrm{a}}$ & $59.80 \pm 0.89^{b}$ & $<0.0001$ \\
\hline CC to coke $(\%)$ & $0.041 \pm 0.002^{\mathrm{c}}$ & $0.044 \pm 0.001^{\mathrm{c}}$ & $0.23 \pm 0.008^{b}$ & $0.019 \pm 0.001^{\mathrm{d}}$ & $0.28 \pm 0.002^{a}$ & $<0.0001$ \\
\hline C conversion to char $(\%)$ & $5.14 \pm 0.74^{\mathrm{d}}$ & $2.96 \pm 1.07^{\mathrm{d}}$ & $18.39 \pm 0.68^{c}$ & $71.02 \pm 0.99^{\mathrm{a}}$ & $59.61 \pm 0.89^{b}$ & $<0.0001$ \\
\hline Global Conversion, X (\%) & $100.00 \pm 0.00^{\mathrm{a}}$ & $99.83 \pm 0.07^{\mathrm{a}}$ & $87.43 \pm 4.21^{\mathrm{b}}$ & $99.97 \pm 0.05^{\mathrm{a}}$ & $100.00 \pm 0.00^{\mathrm{a}}$ & 0.0132 \\
\hline $\mathrm{H}_{2}$ yield (g/g organics) & $0.139 \pm 0.004^{\mathrm{c}}$ & $0.311 \pm 0.001^{\text {a }}$ & $0.172 \pm 0.019^{b}$ & $0.080 \pm 0.002^{\mathrm{d}}$ & $0.073 \pm 0.009^{\mathrm{d}}$ & $<0.0001$ \\
\hline $\mathrm{CO}_{2}$ yield (g/g organics) & $1.258 \pm 0.016^{\mathrm{b}}$ & $2.406 \pm 0.038^{\mathrm{a}}$ & $1.510 \pm 0.197^{b}$ & $0.638 \pm 0.021^{\mathrm{c}}$ & $0.615 \pm 0.100^{\mathrm{c}}$ & 0.0003 \\
\hline Carbon (mg C/g cat g org) & $3 \pm 0^{d}$ & $9 \pm 1^{c}$ & $51 \pm 2^{b}$ & $13 \pm 2^{c}$ & $59 \pm 2^{\text {a }}$ & $<0.001$ \\
\hline
\end{tabular}

$\mathrm{a}, \mathrm{b}, \mathrm{c}$ and $\mathrm{d}$ in each row represent homogeneous groups. Levels not connected by the same letter are statistically different with $95 \%$ confidence

In the case of furfural, a high initial CC gas was obtained. However, a severe catalyst deactivation took place, diminishing the CC gas sharply and resulting in a loss for the CC to gas of around $40 \%$. This result is in agreement with the results obtained for the steam reforming of the aqueous fractions, confirming that furfural is a compound responsible for the deactivation of the catalyst employed in this work.

A low CC gas was obtained during the reforming of both guaiacol and levoglucosan.

However, their evolution over time was different. While for guaiacol a low $\mathrm{CC}$ gas was obtained during the whole experiment, an increase in the $\mathrm{CC}$ gas can be seen during the reforming of levoglucosan. In both cases, the low $\mathrm{CC}$ gas is a consequence of the formation of carbonaceous deposits, which have their origin in an incomplete 
vaporisation of the feed due to the high overall $\mathrm{CC}$ sol (Table 10). Additionally, it is worth mentioning that the excess of water can help the gasification of these carbon deposits, augmenting the $\mathrm{CC}$ gas over time, as can be observed for levoglucosan.

The initial $\mathrm{H}_{2}$ and $\mathrm{CO}_{2}$ yields obtained during the reforming of the selected model compounds decrease as follows: phenol $>$ furfural $>$ acetic acid $>$ guaiacol $>$ levoglucosan. For phenol, furfural and acetic acid the experimental initial $\mathrm{H}_{2}$ and $\mathrm{CO}_{2}$ yields are very close to their thermodynamic yields, and the differences in yields between compounds are due their different reaction stoichiometry (Table 9). In contrast, during the reforming of guaiacol and levoglucosan, a substantial amount of the carbon in the feed is converted into carbon deposits, diminishing both the $\mathrm{H}_{2}$ and $\mathrm{CO}_{2}$ yields. This tendency is consistent with the experimental results obtained during the reforming of the different aqueous fractions.

Interestingly, the reactivity of acetic acid and furfural alone is different than in an organic mixture. A complete (100\%) overall global conversion was obtained for the reforming of the aqueous solution of acetic acid. However, the global conversion for acetic acid during the reforming of the aqueous fractions was lower (around 87\%). This phenomenon might have two plausible explanations. On the one hand, a catalyst deactivation took place during the reforming of the aqueous fractions, while no signs of catalyst deactivation were found during the reforming of acetic acid alone. In addition, a higher $\mathrm{S} / \mathrm{C}$ ratio, which favours the reforming process and helps avoid catalyst deactivation, had to be used. On the other hand, the reactivity of acetic acid could be different when reforming alone than as part of an organic mixture. Interactions between 
chemicals in the aqueous fractions might take place during the reforming process, resulting in the formation of different compounds with a different behaviour in the process [39]. In the case of furfural, a lower overall $2 \mathrm{~h}$ global conversion was obtained during the reforming of the model compound alone than in the aqueous fraction. This result is in concordance with the work of Samolada et. al [39], where higher conversions of furfural were obtained during the catalytic pyrolysis of a furfural/organic mixture than when this compound was treated alone.

\subsubsection{Catalyst deactivation}

Table 10 shows the $\mathrm{CC}$ coke and the amount of $\mathrm{C}$ deposited on the catalyst surface (mg $\mathrm{C} / \mathrm{g}$ catalyst g organic reacted) for the experiments with model compounds. These calculations might help detect the compounds with the highest tendency to deactivate the catalyst. The reforming of levoglucosan gave the highest $\mathrm{CC}$ coke as well as the highest amount of $\mathrm{C}$ deposited on the catalyst surface.

Furfural also provides a high $\mathrm{CC}$ sol and high amount of carbon deposited on the catalyst. This not only confirms the higher deactivation observed during the steam reforming of furfural, but also corroborates the assumption that furfural is to a large extent responsible for the deactivation of the catalyst as well as a major contributor to the deposition of coke during the reforming of the aqueous fractions, as predicted by the statistical analysis of the aqueous fraction results.

Lower $\mathrm{CC}$ coke and amounts of $\mathrm{C}$ deposited on the catalyst were obtained during the reforming of guaiacol, phenol and acetic acid. In the case of guaiacol, the low CC gas 
is a consequence of the high $\mathrm{CC}$ char. This also proves that the high $2 \mathrm{~h}$ overall global conversion for guaiacol $(\mathrm{X})$ is a consequence of its quick transformation to carbon deposits.

3.4 Performance of some compounds in the steam reforming: reactivity vs. coking

Fig. 3 summarises the experimental results obtained in this work regarding reactivity (in terms of global conversion), coke formation and estimated overall potential $\mathrm{H}_{2}$ yield (experimental $\mathrm{H}_{2}$ yield/ thermodynamic $\mathrm{H}_{2}$ yield, \%) for the compounds responsible for the variations observed during the reforming of the aqueous fractions. Specifically, a relative comparison between reactivity and coke formation is provided.

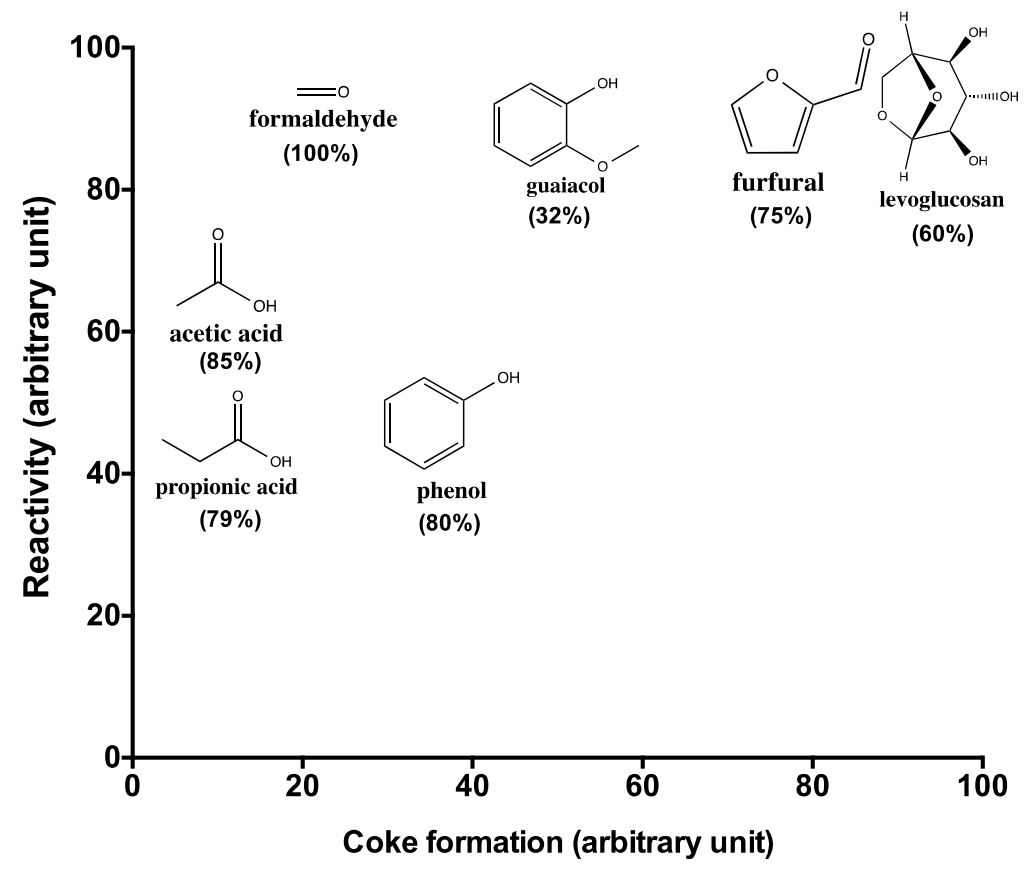

Fig. 3. Relative comparison between reactivity, coke formation and potential $\mathrm{H}_{2}$ yield (in brackets) for the compounds responsible for the variations observed during the reforming of the aqueous fractions. 
The results obtained with the model compounds can explain the differences obtained during the reforming of the aqueous fractions. Acetic acid was identified as a compound with low reactivity and coke formation, while furfural has a high reactivity and coke formation. Consequently, the higher the amount of acetic acid in the aqueous fractions, the lower the deactivation of the catalyst, as explained for the catalytic steam reforming of the aqueous fractions. These results explain the most important trends obtained during the reforming of pine and poplar aqueous fractions, where acetic acid is the compound with the highest variation in concentration between the fractions.

\section{Conclusions}

The catalytic steam reforming of four different aqueous fractions of biomass pyrolysis liquids has been studied in a fixed bed reactor at $650{ }^{\circ} \mathrm{C}$ and atmospheric pressure using a Ni-Co/Al-Mg catalyst. Additional reforming experiments were conducted using aqueous solutions of the following model compounds: acetic acid, phenol, furfural, levoglucosan and guaiacol. The most important conclusions obtained from this work are summarised as follows.

1. The compounds detected and quantified in the aqueous fractions are: carboxylic acids (acetic acid, formic acid and propionic acid), alcohols (methanol), aldehydes (hydroxyacetaldehyde, acetaldehyde and formaldehyde), ketones (2-propanone, 1hydroxy), furans (furfural), sugars (levoglucosan) and aromatic compounds (phenols, guaiacols and syringols). Statistically significant differences in the concentrations of acetic acid, propionic acid, formaldehyde, furfural, levoglucosan and phenols were detected among the four liquids. 
2. During the reforming process, higher initial carbon conversions to gas and greater $\mathrm{H}_{2}$ and $\mathrm{CO}_{2}$ yields were obtained for the aqueous fractions obtained from pine than for those obtained from poplar. The different chemical compositions of the aqueous fractions were responsible for the differences observed during their reforming. These differences are a consequence of the different reactivity of the organic compounds during the reforming process, as well as the different yields to $\mathrm{H}_{2}$ and $\mathrm{CO}_{2}$ that can be obtained with each of the compounds according to their thermodynamics.

3. The reactivity in the reforming process in terms of global conversion for the compounds quantified in the aqueous fractions, under the operating conditions used in this work and when the compounds are part of the liquid mixture, is as follows: aldehydes (hydroxyacetaldehyde, acetaldehyde, formaldehyde $)=$ formic acid $=$ furans $=$ levoglucosan $=$ guaiacols and syringols $>2$-propanone, 1 -hydroxy $>$ methanol $>$ acetic acid $>$ phenols $>$ propionic acid.

4. Among all the compounds with different concentrations in the aqueous fractions, acetic acid and furfural were responsible for the most important differences observed during the catalytic steam reforming of the fractions. Acetic acid was identified as a compound with low reactivity and low coke formation. In contrast, furfural was found to have a high reactivity and a high tendency to produce coke in the reforming process. These were the two compounds mainly responsible for the differences observed in terms of initial $\mathrm{H}_{2}$ and $\mathrm{CO}_{2}$ yields and coke deposition during the reforming of the aqueous fractions used in this work.

5. The additional reforming experiments conducted with the model compounds provided evidence to confirm the conclusions reached during the analysis of the bio-oil aqueous fractions. The initial $\mathrm{H}_{2}$ yields, expressed as $\mathrm{g} \mathrm{H}_{2} / \mathrm{g}$ organic, decrease as 
follows: phenol $>$ furfural $>$ acetic acid $>$ guaiacol $>$ levoglucosan. These results corroborate the high reactivity of furfural in the process and its high tendency to produce coke as well as the low coke formation of acetic acid compared with the other model compounds considered.

6. The statistical tools used in this work for the analysis of the experimental results have proved to be appropriate for studying complex mixtures such as bio-oils. They enabled a correlation to be drawn between the experimental results and chemical compositions, thus enabling identification of the chemical compounds responsible for the most significant variations observed during the reforming of the liquids.

\section{Acknowledgements}

The authors wish to express their gratitude to the Aragón Government (project CTPP02/09) and the Spanish MINECO (projects ENE2010-18985 and ENE201341523-R) for providing financial support and the FPI grant awarded to Javier Remón Núñez (BES- 2011-044856). Furthermore, we would like to thank Ms I. Alava and coworkers at IKERLAN-4 for having provided part of the bio-oil used in the present work. 


\section{References}

[1] Wang D, Montané D, Chornet E. Catalytic steam reforming of biomass-derived oxygenates: acetic acid and hydroxyacetaldehyde. Applied Catalysis A: General. 1996;143:245-70.

[2] Song X, Guo Z. Technologies for direct production of flexible $\mathrm{H}_{2} / \mathrm{CO}$ synthesis gas. Energy Conversion and Management. 2006;47:560-9.

[3] Sipillä K, Kuoppala E, Fagernas L, Oasmaa A. Characterization of biomass-based flash pyrolysis oils. Biomass Bioenerg. 1998;14:103-13.

[4] Wang S, Li X, Zhang F, Cai Q, Wang Y, Luo Z. Bio-oil catalytic reforming without steam addition: Application to hydrogen production and studies on its mechanism. Int J Hydrogen Energy. 2013;38:16038-47.

[5] Trane R, Dahl S, Skjøth-Rasmussen MS, Jensen AD. Catalytic steam reforming of bio-oil. Int J Hydrogen Energy. 2012;37:6447-72.

[6] Bimbela F, Chen D, Ruiz J, García L, Arauzo J. Ni/Al coprecipitated catalysts modified with magnesium and copper for the catalytic steam reforming of model compounds from biomass pyrolysis liquids. Applied Catalysis B: Environmental. 2012;119-120:1-12.

[7] Bimbela F, Oliva M, Ruiz J, García L, Arauzo J. Catalytic steam reforming of model compounds of biomass pyrolysis liquids in fixed bed: Acetol and n-butanol. Journal of Analytical and Applied Pyrolysis. 2009;85:204-13.

[8] Medrano JA, Oliva M, Ruiz J, García L, Arauzo J. Catalytic steam reforming of model compounds of biomass pyrolysis liquids in fluidized bed reactor with modified Ni/Al catalysts. Journal of Analytical and Applied Pyrolysis. 2009;85:21425.

[9] Rioche C, Kulkarni S, Meunier FC, Breen JP, Burch R. Steam reforming of model compounds and fast pyrolysis bio-oil on supported noble metal catalysts. Applied Catalysis B: Environmental. 2005;61:130-9.

[10] $\mathrm{Hu}$ X, Lu G. Investigation of the steam reforming of a series of model compounds derived from bio-oil for hydrogen production. Applied Catalysis B: Environmental. 2009;88:376-85.

[11] Marquevich M, Czernik S, Chornet E, Montané D. Hydrogen from Biomass: Steam Reforming of Model Compounds of Fast-Pyrolysis Oil. Energy \& Fuels. 1999;13:1160-6.

[12] Vagia E, Lemonidou A. Thermodynamic analysis of hydrogen production via steam reforming of selected components of aqueous bio-oil fraction. Int J Hydrogen Energy. 2007;32:212-23.

[13] Wang S, Cai Q, Zhang F, Li X, Zhang L, Luo Z. Hydrogen production via catalytic reforming of the bio-oil model compounds: Acetic acid, phenol and

hydroxyacetone. Int J Hydrogen Energy. 2014;39:18675-87.

[14] Wang S, Zhang F, Cai Q, Li X, Zhu L, Wang Q, et al. Catalytic steam reforming of bio-oil model compounds for hydrogen production over coal ash supported $\mathrm{Ni}$ catalyst. Int J Hydrogen Energy. 2014;39:2018-25.

[15] Wu C, Sui M, Yan YJ. A Comparison of Steam Reforming of Two Model Bio-Oil Fractions. Chem Eng Technol. 2008;31:1748-53.

[16] Bimbela F, Oliva M, Ruiz J, García L, Arauzo J. Hydrogen production via catalytic steam reforming of the aqueous fraction of bio-oil using nickel-based coprecipitated catalysts. Int J Hydrogen Energy. 2013;38:14476-87. 
[17] Bertero M, Sedran U. Conversion of pine sawdust bio-oil (raw and thermally processed) over equilibrium FCC catalysts. Bioresource technology. 2013;135:64451.

[18] Basagiannis AC, Verykios XE. Steam reforming of the aqueous fraction of biooil over structured $\mathrm{Ru} / \mathrm{MgO} / \mathrm{Al}_{2} \mathrm{O}_{3}$ catalysts. Catalysis Today. 2007;127:256-64. [19] García L, French R, Czernik S, Chornet E. Catalytic steam reforming of bio-oils for the production of hydrogen: effects of catalyst composition. Applied Catalysis A: General. 2000;201:225-39.

[20] Li H, Xu Q, Xue H, Yan Y. Catalytic reforming of the aqueous phase derived from fast-pyrolysis of biomass. Renewable Energy. 2009;34:2872-7.

[21] Medrano JA, Oliva M, Ruiz J, Garcia L, Arauzo J. Hydrogen from aqueous fraction of biomass pyrolysis liquids by catalytic steam reforming in fluidized bed. Energy. 2011;36:2215-24.

[22] Remón J, Broust F, Valette J, Chhiti Y, Alava I, Fernandez-Akarregi AR, et al. Production of a hydrogen-rich gas from fast pyrolysis bio-oils: Comparison between homogeneous and catalytic steam reforming routes. Int J Hydrogen Energy. 2014;39:171-82.

[23] Remón J, Medrano JA, Bimbela F, García L, Arauzo J. Ni/Al-Mg-O solids modified with $\mathrm{Co}$ or $\mathrm{Cu}$ for the catalytic steam reforming of bio-oil. Applied Catalysis B: Environmental. 2013;132-133:433-44.

[24] Hilmen AM, Schanke D, Holmen A. TPR study of the mechanism of rhenium promotion of alumina-supported cobalt Fischer-Tropsch catalysts. Catalysis Letters. 1996;38:143-7.

[25] Jongsomjit B, Panpranot J, Goodwin Jr JG. Co-Support Compound Formation in Alumina-Supported Cobalt Catalysts. Journal of Catalysis. 2001;204:98-109. [26] Kogelbauer A, Goodwin JG, Oukaci R. Ruthenium promotion of $\mathrm{Co} / \mathrm{Al}_{2} \mathrm{O}_{3}$ Fischer-Tropsch catalysts. Journal of Catalysis. 1996;160:125-33. [27] Fukuda K. BIC-based unit-root detection: Simulation-based evidence. Applied Mathematics and Computation. 2006;183:518-21.

[28] Wei J, Zhou L. Model selection using modified AIC and BIC in joint modeling of paired functional data. Statistics \& Probability Letters. 2010;80:1918-24.

[29] Ayalur Chattanathan S, Adhikari S, Abdoulmoumine N. A review on current status of hydrogen production from bio-oil. Renewable and Sustainable Energy Reviews. 2012;16:2366-72.

[30] Bertero M, de la Puente G, Sedran U. Fuels from bio-oils: Bio-oil production from different residual sources, characterization and thermal conditioning. Fuel. 2012;95:263-71.

[31] Gu X, Ma X, Li L, Liu C, Cheng K, Li Z. Pyrolysis of poplar wood sawdust by TGFTIR and Py-GC/MS. Journal of Analytical and Applied Pyrolysis. 2013;102:16-23. [32] Ramachandran RPB, van Rossum G, van Swaaij WPM, Kersten SRA. Evaporation of Biomass Fast Pyrolysis Oil: Evaluation of Char Formation. Environmental Progress \& Sustainable Energy. 2009;28:410-7. [33] Bimbela F, Oliva M, Ruiz J, García L, Arauzo J. Hydrogen production by catalytic steam reforming of acetic acid, a model compound of biomass pyrolysis liquids. Journal of Analytical and Applied Pyrolysis. 2007;79:112-20.

[34] Medrano JA, Oliva M, Ruiz J, Garcia L, Arauzo J. Catalytic steam reforming of acetic acid in a fluidized bed reactor with oxygen addition. Int J Hydrogen Energy. 2008;33:4387-96. 
[35] Medrano JA, Oliva M, Ruiz J, García L, Arauzo J. Catalytic steam reforming of butanol in a fluidized bed and comparison with other oxygenated compounds. Fuel Processing Technology. 2014;124:123-33.

[36] Wang Y, Mourant D, Hu X, Zhang S, Lievens C, Li C-Z. Formation of coke during the pyrolysis of bio-oil. Fuel. 2013;108:439-44.

[37] Di Felice L, Courson C, Foscolo PU, Kiennemann A. Iron and nickel doped alkaline-earth catalysts for biomass gasification with simultaneous tar reformation and $\mathrm{CO}_{2}$ capture. Int J Hydrogen Energy. 2011;36:5296-310.

[38] Wang Y, Hu X, Mourant D, Song Y, Zhang L, Lievens C, et al. Evolution of aromatic structures during the reforming of bio-oil: Importance of the interactions among bio-oil components. Fuel. 2013;111:805-12.

[39] Samolada MC, Papafotica A, Vasalos IA. Catalyst evaluation for catalytic biomass pyrolysis. Energy \& Fuels. 2000;14:1161-7. 